\title{
A Brief Review of Specialty Optical Fibers for Brillouin-Scattering-Based Distributed Sensors
}

\author{
Peter Dragic $^{1, *}$ and John Ballato ${ }^{2}$ \\ 1 Department of Electrical and Computer Engineering, University of Illinois at Urbana-Champaign, \\ Urbana, IL 61801, USA \\ 2 Department of Materials Science and Chemistry, Clemson University, Clemson, SC 29631, USA; \\ jballat@clemson.edu \\ * Correspondence: p-dragic@illinois.edu; Tel.: +1-217-333-8399
}

Received: 13 September 2018; Accepted: 17 October 2018; Published: 20 October 2018

\begin{abstract}
Specialty optical fibers employed in Brillouin-based distributed sensors are briefly reviewed. The optical and acoustic waveguide properties of silicate glass optical fiber first are examined with the goal of constructing a designer Brillouin gain spectrum. Next, materials and their effects on the relevant Brillouin scattering properties are discussed. Finally, optical fiber configurations are reviewed, with attention paid to fibers for discriminative or other enhanced sensing configurations. The goal of this brief review is to reinforce the importance of fiber design to distributed sensor systems, generally, and to inspire new thinking in the use of fibers for this sensing application.
\end{abstract}

Keywords: Brillouin scattering; specialty optical fibers; glass materials; optical fiber; fiber sensors; acoustic properties

\section{Introduction}

In comparison to the available configurations for distributed fiber sensing, those that are Brillouin scattering-based appear to offer somewhat superior spatial resolution with a long sensor reach [1]. However, despite several such appealing advantages, they have captured (and are expected to capture) only a marginal share of the total commercial distributed fiber sensor market [2]. While application requirements certainly lead one's choosing the most appropriate sensor type, relative cost, without doubt, is a recognized disadvantage for Brillouin-based systems [3]. Hence, in response came the development of new system architectures, including Brillouin optical correlation domain reflectometry (BOCDR) [4,5]. Nevertheless, the mundane commonality among nearly all Brillouin-based systems, whether for reasons of cost, convenience, or ubiquity, is the use of standard (i.e., telecommunications) single mode fiber as the key sensing element.

There are a wide variety of very good reviews that focus on, or include a discussion of, Brillouin-based distributed sensing systems for numerous applications [1,6-15]. Most of these focus on the system architecture. However, as discussed here, there is an emerging body of work focusing on fiber design as a path towards system simplification and improvement. A subset of these even focus on novel materials, for example to realize fibers with custom thermo-mechanical response. The purpose of this paper is to offer a brief review of some of these novel fiber configurations, with a focus on the importance of the enabling material in these approaches. While Brillouin scattering has been studied in micro-structured fiber [16-20], and non-silicate systems, including phosphate [21], tellurite [22], ZBLAN [23], and chalcogenide $\left(\mathrm{As}_{2} \mathrm{Se}_{3}\right.$ [24,25] and $\mathrm{As}_{2} \mathrm{~S}_{3}$ [25]) glasses, this review will focuse on solid singly- or multiply-clad, circular-geometry fibers in silicate glass systems. Such configurations offer the best compatibility with conventional components and fiber fabrication processes. 
Ultimately, it is the hope of the authors that this brief review will serve to (at least partly) reinforce the importance of, and need for, fiber and material design in distributed sensor systems, generally. This paper is written from the perspective of fiber makers and designers, and therefore new system-level analyses (such as sensitivity, sensor configurations, etc.) are not considered. Rather, without prejudice toward any one approach, and with apologies to those not described herein, a wide variety of fiber technologies are described with the hopes of inspiring novel thinking with regard to distributed sensor systems based on Brillouin scattering. That said, the remainder of this paper is arranged as follows. The next section focuses on the waveguide properties of the optical fiber, both acoustic and optical, and, from that, other basic features, such as the Brillouin gain spectrum, are formulated. After that, a discussion of materials, both more and less common, is provided, with some focus on the fiber thermo-mechanical response. This, then, leads into a discussion of tailored fiber configurations and concomitant sensing approaches, with some focus on discriminative sensing. Finally, the paper concludes with a few closing remarks and future perspectives.

\section{The Waveguide}

Optical fiber has gained the status of omnipresence in the modern, technologically-connected world. Even for those without scientific training, the operating principle behind optical fiber can intuitively be understood. Indeed, more than 150 years ago, John Tyndall left an indelible mark with his public lectures demonstrating the guidance of light through a laminar flow of water [26]. Most school children in a science class have witnessed some form of this demonstration, and the notion of total internal reflection (TIR) and guidance can conceptually be understood through observation. Although calculations of modes, propagation constants, dispersion coefficients, etc. mathematically are somewhat more complex [27], the simple ray propagation picture suffices to illustratively explain how a thin strand of glass can propagate a signal with losses now as low as $0.14 \mathrm{~dB} / \mathrm{km}$ [28]. As Kao and Hockham predicted, however, this achievement largely has been enabled by materials science and engineering [29].

An optical fiber is described by its refractive index profile (RIP). Figure 1 shows an example of a very simple RIP for a conventional, step-index optical fiber. The central part of the structure, the core, guides light. Its refractive index $\left(n_{\text {core }}\right)$ is greater than that of the cladding $\left(n_{\text {clad }}\right)$, therefore satisfying the main requirement for TIR. The cladding diameter ( $2 \mathrm{~b}$, typically $125 \mu \mathrm{m}$ as a standard for telecommunications fiber) is considered to be infinite in most mathematical treatments of the fiber. It is coated with a buffer material, serving both to provide mechanical strength to the fiber, and to provide filtering/removal of any light propagating in the cladding due to scattering, bending, or other losses attributable to optical coupling at interfaces. Hence, the buffer usually has a refractive index higher than that of the cladding. Such a structure has perfect guidance, whose propagation constants are purely real-valued.



Figure 1. Refractive index profile (RIP) for a conventional step-index optical fiber. 
Within this structure, the optical wave interacts with one or more acoustic waves, forming the basis for Brillouin scattering in optical fiber. Therefore, it is the optical mode, its effective index (determined from the propagation constant), and its spatial distribution in the fiber (or in other words, how the mode overlaps with different regions of the waveguide) that give rise to the measurements made in the process of distributed sensing. The modes are calculated by solving Maxwell's Wave Equation subject to the boundary conditions in cylindrical symmetry [30] in the usual way. The effective area, relating to the field intensity, is given by

$$
A_{e f f}=\frac{\left(\int_{0}^{2 \pi} \int_{0}^{\infty} r E(r, \theta) E^{*}(r, \theta) d r d \theta\right)^{2}}{\int_{0}^{2 \pi} \int_{0}^{\infty} r\left(E(r, \theta) E^{*}(r, \theta)\right)^{2} d r d \theta}
$$

where $E(r, \theta)$ is the electric field distribution (in the radial and azimuthal directions) and $E^{*}(r, \theta)$ is the complex conjugate. Intensity is particularly important as it sets the absolute gain in a nonlinear process such as Brillouin scattering.

Brillouin scattering typically manifests as an interaction between the optical wave and a longitudinal-type sound (or pressure) wave. The interaction itself arises from axially-periodic perturbations to the permittivity due to the pressure associated with the sound wave. It is governed by the Bragg condition $\lambda_{a}=\lambda_{o} / 2 n_{\text {eff }}$ where $\lambda_{a}$ is the acoustic wavelength, $\lambda_{o}$ is the vacuum optical wavelength, and $n_{\text {eff }}$ is the effective index of the optical mode. The acoustic wavelength also may be expressed in terms of the acoustic velocity, $V_{a}$, via $V_{a}=\lambda_{a} v_{a}$ where $v_{a}$ is the frequency of the acoustic wave (in the hypersonic range). It is important to recognize that the optical and acoustic wavelengths are of comparable magnitude (indeed, only a factor of 2 between them). As such, the optical fiber would naturally be expected to exhibit acoustic waveguide effects. This would then suggest that $V_{a}$ should be considered to be the phase velocity of the acoustic mode.

Thus, similar to the optical RIP, a radial profile can be identified that describes the acoustic waveguide. Usually, the acoustic velocity itself serves in this capacity (vertical scale in Figure 1), but an "acoustic index" also may be utilized. Usually, this is defined as the cladding acoustic velocity divided by the material acoustic velocity in the radial direction [31]. Therefore, similar to the optical waveguide, the core should have an acoustic index that is greater than that of the cladding to satisfy some analogous TIR in the acoustic realm. Logically, since the acoustic wave is key to the sensing mechanism, one may quickly conclude that guiding them might somehow improve system performance.

With this in mind, the fiber possesses two important profiles: (1) the optical RIP; and (2) the acoustic velocity profiles. Jen et al. [32] describes a procedure by which, depending on the dopants used (in silica), a glass fibers' optical and acoustic profiles may independently be designed. In other words, one can realize, for example, a fiber that guides optical waves, but is anti-guiding to acoustic waves. More complicated structures, such as fibers with cores whose optical index or acoustic velocity vary in the radial direction, also become possible. As a result, charts such as that shown in Table 1 typically are used to show the effects of the dopant on the optical $\left(n_{0}\right)$ or acoustic $\left(n_{a}\right)$ index of the silicate glass. They assist in the selection of materials for a specific fiber design. Interestingly, in Table 1, all but alumina raise the acoustic index (reduce the acoustic velocity). Only recently has it been confirmed in fiber form that both $\mathrm{MgO}$ [33] and $\mathrm{Li}_{2} \mathrm{O}$ [34] act in a manner similar to alumina, in raising the acoustic velocity when added to silica. An extensive study on these and several other relevant acoustic properties can be found in [35]. The next section provides additional details regarding the material and enumerate of the effects of the various dopants. 
Table 1. The effect of some common dopants on the optical and acoustic index of silica. RE stands for rare earth. The arrows represent, in the obvious way, an increase or decrease in a material value when added to silica.

\begin{tabular}{ccccccccc}
\hline & $\mathrm{GeO}_{2}$ & $\mathbf{P}_{2} \mathrm{O}_{5}$ & $\mathrm{TiO}_{2}$ & $\mathbf{B}_{2} \mathrm{O}_{3}$ & $\mathbf{F}$ & $\mathrm{Al}_{2} \mathrm{O}_{3}$ & $\mathrm{Y}_{2} \mathrm{O}_{3}$ & $\mathrm{RE}_{2} \mathrm{O}_{3}$ \\
\hline$n_{o}$ & $\uparrow$ & $\uparrow$ & $\uparrow$ & $\downarrow$ & $\downarrow$ & $\uparrow$ & $\uparrow$ & $\uparrow$ \\
$n_{a}$ & $\uparrow$ & $\uparrow$ & $\uparrow$ & $\uparrow$ & $\uparrow$ & $\downarrow$ & $\downarrow$ & $\uparrow$ \\
\hline
\end{tabular}

Determination of the acoustic phase velocity (or the acoustic modes), therefore, requires solving an acoustic wave equation subject to the relevant boundary conditions. The acoustic waves obey a damped wave equation given by $[36,37]$

$$
\rho \ddot{u}-\bar{\nabla} \cdot[\overline{\bar{c}} \nabla u+\overline{\bar{\eta}} \nabla \dot{u}]=-\frac{1}{2} \bar{\nabla} \cdot\left[\overline{\bar{\gamma}} E_{k} E_{l}\right]
$$

where the electrostrictive coefficients are given by a fourth rank tensor in $\overline{\bar{\gamma}}$, the damping term, $\overline{\bar{\eta}}$, is a tensor of rank four, and $\overline{\bar{c}}$ is the rank-four elastic modulus tensor. $\vec{u}$ is the displacement field (and $\dot{u}$ is its time derivative) associated with the sound wave and can take on values in any of the directions in cylindrical coordinates. Thomas et al. [38] provided a detailed mathematical and experimental analysis of the scattering of light waves from acoustic modes of an optical fiber whose cladding velocity is less than that of the core (acoustically anti-guiding, pure silica core with a borosilicate cladding). Roughly 10 years later, Jen and colleagues [39-41] offered thorough mathematical analyses of fibers configured to be acoustically guiding. It was about the same time that Shibata et al. [42,43] made some of the first observations of multi-peaked Brillouin spectra, which they attributed to the presence of multiple guided acoustic modes.

The scattering integral that ultimately provides the strength of the Brillouin interaction is [38]

$$
D_{p, q}=\int_{V o l} E_{p}^{*} \delta \varepsilon_{p, q} E_{q} d V
$$

where $p, q=r, \phi, z$ are the cylindrical coordinates, $E$ is the electric field, and $\delta \varepsilon$ are the dielectric perturbations resulting from the pressure wave (or strain field). The relevant dielectric perturbations $\left(\delta \varepsilon_{p, q}\right)$ are functions of the acoustic strain fields $\left(S_{p, q}\right)$ and are given by $[38,43]$

$$
\begin{gathered}
\delta \varepsilon_{r r}=-\varepsilon_{0} n_{o}^{4}\left(p_{11} S_{r r}+p_{12} S_{\phi \phi}+p_{12} S_{z z}\right) \\
\delta \varepsilon_{\phi \phi}=-\varepsilon_{0} n_{o}^{4}\left(p_{11} S_{\phi \phi}+p_{12} S_{r r}+p_{12} S_{z z}\right) \\
\delta \varepsilon_{\phi r}=-\varepsilon_{0} n_{o}^{4} 2 p_{44} S_{\phi r}
\end{gathered}
$$

where $\varepsilon_{0}$ is the permittivity of free space and the $p_{i j} \mathrm{~s}$ are the usual photoelastic coefficients of the material. The generalized form of the acoustic strain field can be written as a function of the displacement vector [36,37]

$$
S_{p q}=\frac{1}{2}\left(\frac{\partial u_{q}}{\partial p}+\frac{\partial u_{p}}{\partial q}\right)
$$

The displacement vector now remains to be found. In the case of the fiber structure of Figure 1, the cladding is taken to be infinite and so there is one boundary at $r=a$. To determine the acoustic propagation constant(s), the boundary conditions are applied to assumed solutions $(u(r, \phi, z))$ of the wave equations (Bessel functions in this case). In the case of the acoustic waveguide, there are four boundary conditions. First, the displacement vector must be continuous at any interface. Second, the two shear stresses at the interface and the normal compressional stress must be continuous at any boundary. These can be found mathematically listed in [44]. Once the propagation constants are determined by solving the characteristic matrix equation, they can be utilized to determine the spatial 
distribution of the displacement vector for the subsequent analysis. Similar, more recent approaches to calculating the longitudinal acoustic modes of an optical fiber can be found in several places [44-46].

The solutions to the wave equation are acoustic modes that have radial, longitudinal, and azimuthal components [38]. The fundamental optical mode in the fiber is azimuthally-symmetric, and therefore will have greatest overlap with azimuthally-symmetric acoustic modes. Shibata et al. [43] identified these as axial-radial modes $R_{0 \mathrm{~m}}$, but which are dominated by the longitudinal component $\left(\mathrm{L}_{0 \mathrm{~m}}\right)$. Nevertheless, the presence of these radial wave components causes the propagation constants, even in acoustically guiding fibers, to be complex-valued (unlike with the optical waves). Simply put, the wave phase velocity exceeds the shear velocity in both the core and cladding; the Bessel functions become complex (Hankel) functions in the cladding (by assuming that it is infinite in extent), giving rise to radiation, or leaky, modes [39]. The complex propagation constant can be expressed as $\beta=k_{a}-j \gamma_{w g}$ and, therefore, a z-propagating displacement field will take the form $\tilde{\mathrm{u}} \sim e^{-j \beta z}=e^{-\gamma_{w g} z} e^{-j k_{a} z}$, possessing an attenuation term associated with the radiation of acoustic energy. In the case of acoustically guiding fibers, this additional attenuation term is far less in magnitude than the intrinsic (viscoelastic) material damping loss and can be neglected. Interestingly, should the density and shear velocity values be the same in the core and cladding, the waveguide loss term vanishes [39]. Making this approximation can then simplify the mathematical analysis to some extent. In the case of acoustically anti-guiding fibers, the longitudinal wave also becomes leaky (again assuming an infinite cladding) and can contribute waveguide loss comparable to, or even much larger than [47] that of the material [44]. As discussed below, this acts to broaden the Brillouin gain spectrum (BGS) and reduce the peak gain coefficient; potentially undesirable characteristics for some distributed sensor applications.

Ultimately, the determination (or design) of the BGS is the desired outcome. Therefore, once the components of the displacement vector are known, the scattering amplitude can be determined. Using similar modal symmetry arguments as above, the analyses in $[38,40,42]$ show that the dominant scattering term arises from the $p_{12} S_{z z}$ contribution. Therefore, the scattering integral in Equation (3) can be replaced by a simplified (and normalized) overlap integral taking the form [48]

$$
\Gamma_{m}^{1 / 2}=\frac{\int_{0}^{\infty} \vec{E}^{*}(r) u_{z, 0 m}(r) \vec{E}(r) r d r}{\sqrt{\left(\int_{0}^{\infty}\left|u_{z, 0 m}(r)\right|^{2} r d r\right)\left(\int_{0}^{\infty}|\vec{E}(r)|^{4} r d r\right)}}
$$

Owing to the simple exponential decay of the acoustic wave, a BGS possesses the natural (or Lorentzian) lineshape [49], with the possibility of multiple overlapping peaks given the presence of multiple acoustic modes possessing non-zero overlap with the optical field [42]. The scattered intensity is proportional to $\Gamma_{m}$ [38], and, therefore, the BGS can be calculated by the following

$$
B G S=\sum_{m} g_{B}\left(v_{a_{0 m}}\right) \frac{\left(\Delta v_{B_{0 m}} / 2\right)^{2}}{\left(v-v_{a_{0 m}}\right)^{2}+\left(\Delta v_{B_{0 m}} / 2\right)^{2}} \Gamma_{m}
$$

where $\Delta v_{B}$ is the spectral width of the mode, which possesses contributions from both material damping and acoustic waveguide-based losses. As previously stated, the waveguide part can be neglected for typical acoustically-guiding fiber. $g_{B}$ is the Brillouin gain coefficient, which possesses a number of material parameters, including the photoelastic constant, $p_{12}$, which is dropped from the normalized overlap integral, and given by [49]

$$
g_{B}\left(v_{B}\right)=\frac{2 \pi n^{7} p_{12}^{2}}{c \lambda_{o}^{2} \rho V_{a} \Delta v_{B}}
$$


with all the material properties previously defined, except for the mass density, $\rho$. In general, this equation should not have a wavelength dependence. $\Delta v_{B}$, if only resulting from material damping, typically is proportional to $v_{a}^{2}$, which, in turn, is proportional to $\lambda_{o}{ }^{-2}$ thereby canceling the wavelength dependence in the denominator. This is discussed in the next section. However, there may be chromatic dispersion in the index [50] or photoelastic constant [51-53], or it is possible that each acoustic mode possesses a unique $g_{B}$ (more on this later).

Now, a very simple example calculation of the BGS is presented. Figure 2 shows the RIP and longitudinal acoustic velocity profile for a fictitious fiber wherein all acoustic modes have the same $\Delta v_{B}=35 \mathrm{MHz}$ and the same $g_{B}$. How these profiles came to be, with regard to the dopants in Table 1 , is not important for this example, although this is briefly revisited in the next section. Following the procedure outlined above, $n_{\text {eff }}$ is calculated first, establishing the acoustic wavelength and eventually the real part of the acoustic propagation constant. Next, the boundary conditions are applied, from which the imaginary part of the propagation and the acoustic phase velocity are found. The modes then can be plotted to determine the overlap integral given by Equation (8) and the BGS can be constructed using Equation (9). The result is shown in Figure 3. The relative gain coefficient in this case is dominated by the overlap between the acoustic and optical modes. As can be seen by the inset, visually, the $\mathrm{L}_{01}$ acoustic mode clearly has the highest overlap with the $\mathrm{LP}_{01}$ optical mode (optical intensity is shown in red). Higher order acoustic modes (HOAMs) become more oscillatory, and therefore the overlap steadily decreases with increasing mode number, with the $\mathrm{LP}_{01}-\mathrm{L}_{04}$ interaction no longer visible above the tails of the other interactions. The acoustic waveguide is clearly multimode, supporting a fundamental and three HOAMs in the $\mathrm{L}_{0 \mathrm{~m}}$ mode family.



Figure 2. RIP and longitudinal acoustic velocity profile for the fiber of the example.

The optical and acoustic profiles were selected for this example since they give rise to HOAM interactions of reasonable strength. In this case, the $\mathrm{LP}_{01}-\mathrm{L}_{01}$ overlap integral (Equation (8)) is about $87 \%$. This "relatively low" value results from the acoustic mode possessing a smaller diameter than the optical mode, providing for enhanced overlap with the HOAMs. In a way fully analogous to the optical mode, bringing the core and cladding acoustic velocity values closer together widens the fundamental acoustic mode and enhances this overlap. Increasing the core acoustic velocity to $5920 \mathrm{~m} / \mathrm{s}$ increases the overlap integral between the fundamental modes to roughly $93 \%$, while at the same time $\mathrm{L}_{03}$ and $\mathrm{L}_{04}$ become cut off. When the velocity difference decreases to $35 \mathrm{~m} / \mathrm{s}$ the $\mathrm{L}_{02}$ mode becomes cut off. Focusing now on the core diameter, increasing it may result in an increase in the number of propagating modes. For instance, setting the core diameter to $9 \mu \mathrm{m}$ (similar to conventional single mode fiber, with all else kept the same) adds the $\mathrm{L}_{05}$ and $\mathrm{L}_{06}$ mode interactions, though the latter is near cutoff. This also results in an $\mathrm{LP}_{01}-\mathrm{L}_{01}$ overlap integral of approximately $97 \%$. The $\mathrm{L}_{07}$ becomes guided when the core diameter is increased to $10.8 \mu \mathrm{m}$, but the optical V-Number then is only just below cutoff for single mode behavior at $1534 \mathrm{~nm}$.

While a dominant acoustic mode may seem most desirable from the perspective of maximizing the Brillouin gain, there are cases where multiple peaks are instead desirable. The example presented 
above is for a simple step-index fiber where the acoustic and optical waveguide boundaries coincide. This usually leads to a dominant $\mathrm{L}_{01}$ mode interaction, where fiber optical properties are still well within typical requirements (single mode, low bending loss, etc.). However, given the wide range of materials available in the fabrication of fiber, the RIP and acoustic velocity profiles can be tailored independently, though with some restrictions. With that, it is therefore possible to design a fiber that is multi-layered, both optically and acoustically, and with boundaries that need not coincide, although this can render fabrication extremely, or even prohibitively, difficult. These configurations are discussed in Section 4. However, first, tailoring the fiber profiles necessarily requires doping material into silica, each of which brings about different changes to the parameters that contribute to Equation (10), and results in materials with differing response to the thermo-mechanical environment. This is another important consideration that is addressed in the next section.

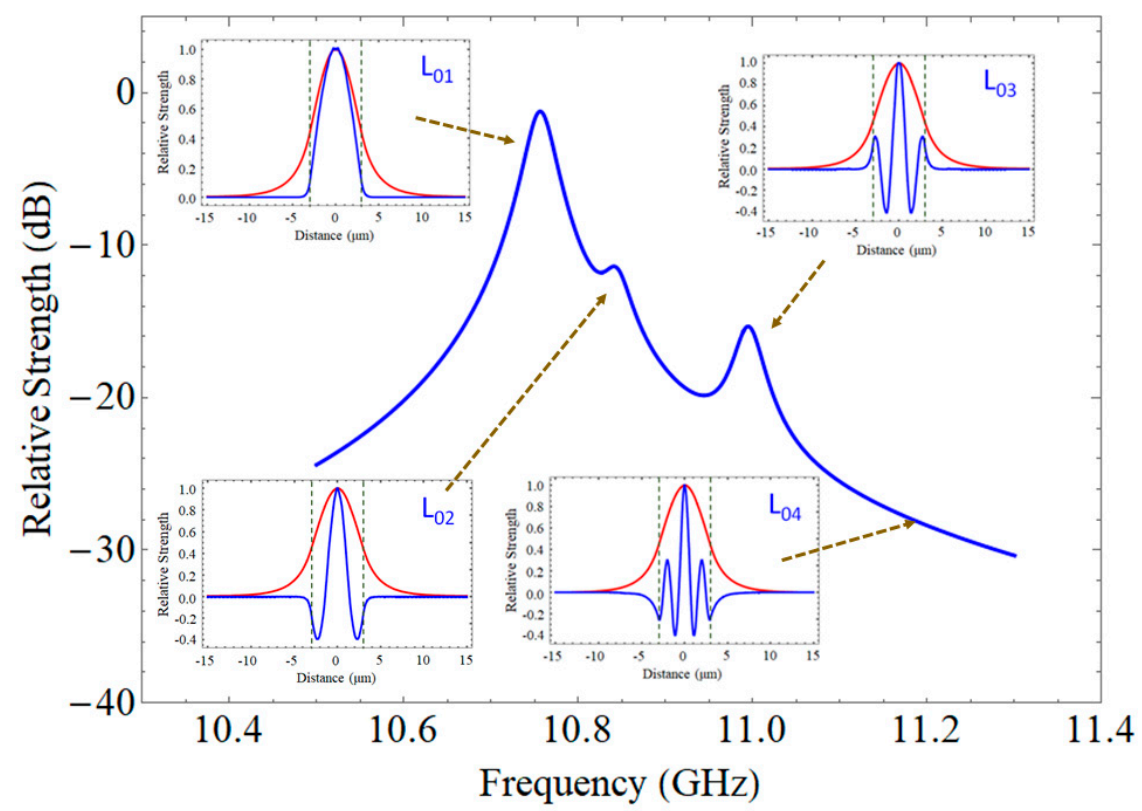

Figure 3. Simulated Brillouin gain spectrum (BGS) calculated $(1534 \mathrm{~nm})$ from the profiles in Figure 2. The positions of the longitudinal mode interactions are also shown. The insets plot the $\mathrm{LP}_{01}$ optical mode intensity (red) and the acoustic displacement $u_{z}(r)$ (blue). Vertical dashed lines in the insets delineate the core region.

\section{The Material}

The previous section reviewed the acoustic waveguide properties of the optical fiber. In this section, the focus shifts to the material and the influence of dopants on those physical properties of silica glass which are relevant to Brillouin scattering. From the perspective of the waveguide, the acoustic velocity values are most important. The longitudinal and shear velocity values are related to the Lamé constants ( $\lambda_{L}$ and $\mu_{L}$ where the subscript $L$ has been added for disambiguation) as $V_{L}=\sqrt{\left(\lambda_{L}+2 \mu_{L}\right) / \rho}$ and $V_{S}=\sqrt{\mu_{L} / \rho}$, respectively. The numerators within square root are the longitudinal and shear elastic moduli. For the sake of simplicity, the acoustic velocities, rather than the elastic moduli, are considered the key design parameter.

To form the acoustic (or optical) waveguide, some amount of dopant should be added to the base silica glass. For the present analysis, these come in the form of oxide and F additives. To form an acoustic waveguide, a material that reduces the acoustic velocity when added to silica is desired. Optical guidance requires that this dopant also raise the refractive index. Jen et al. [54,55] offered a detailed ultrasonic and optical analysis of doped fiber preforms, giving rise to the empirical design coefficients provided in Table 2. These coefficients suggest a linear dependence of the parameters on the dopant concentration in percentage by weight. This relationship does not necessarily hold for 
all dopants and parameters. See, for example, the index of binary phosphosilicate glass [56] where linearity in the mole \% (mol\%) of $\mathrm{P}_{2} \mathrm{O}_{5}$ was observed up to $40 \mathrm{~mol} \%$. There is not a linear relationship between $\mathrm{P}_{2} \mathrm{O}_{5}$ concentration expressed in weight $\%(\mathrm{wt} \%)$ and in $\mathrm{mol} \%$. Regardless, these linear values can hold over small, but significant, compositional ranges. Several more such empirical design equations have been provided over the years. For instance, Koyamada et al. [45] summarized data from [57-59] giving the following

$$
\begin{gathered}
n=1.458\left(1+1.0 \times 10^{-3}\left[\mathrm{GeO}_{2}\right]_{w t \%}-3.3 \times 10^{-3}[\mathrm{~F}]_{w t \%}\right) \\
V_{L}=5944\left(1-7.2 \times 10^{-3}\left[\mathrm{GeO}_{2}\right]_{w t \%}-2.7 \times 10^{-2}[\mathrm{~F}]_{w t \%}\right)(\mathrm{m} / \mathrm{s}) \\
V_{S}=3749\left(1-6.4 \times 10^{-3}\left[\mathrm{GeO}_{2}\right]_{w t \%}-2.7 \times 10^{-2}[\mathrm{~F}]_{w t \%}\right)(\mathrm{m} / \mathrm{s}) \\
\rho=2202\left(1+6.4 \times 10^{-3}\left[\mathrm{GeO}_{2}\right]_{w t \%}-3.4 \times 10^{-3}[\mathrm{~F}]_{w t \%}\right)\left(\mathrm{kg} / \mathrm{m}^{3}\right)
\end{gathered}
$$

where the number in brackets is the composition in $\mathrm{wt} \%$. These values appear to have been at least partly adopted by others [60-62]. What is particularly interesting is that this set of equations now enables the design of ternary glass compositions. Presumably, any number of additional dopants could be appended to these equations. Using them, the composition of the core necessary to achieve the example profiles in Figure 2 is $0.5 \mathrm{wt} \% \mathrm{~F}$ and $4.4 \mathrm{wt} \% \mathrm{GeO}_{2}$ in silica (but assuming that pure silica has an acoustic velocity of $5970 \mathrm{~m} / \mathrm{s}$ [35]).

Table 2. Empirical effect of some common dopants on the optical index and shear and longitudinal acoustic velocities of silica. Data from [55].

\begin{tabular}{cccc}
\hline Dopant & $\boldsymbol{\Delta} \boldsymbol{n}(\mathbf{\%} / \mathbf{w t} \%)$ & $\Delta \boldsymbol{V}_{\boldsymbol{S}}(\mathbf{\%} / \mathbf{w t} \%)$ & $\boldsymbol{\Delta} \boldsymbol{V}_{\boldsymbol{L}} \mathbf{( \% / \mathbf { w t } \% )}$ \\
\hline $\mathrm{GeO}_{2}$ & +0.056 & -0.49 & -0.47 \\
$\mathrm{P}_{2} \mathrm{O}_{5}$ & +0.020 & -0.41 & -0.31 \\
$\mathrm{~F}$ & -0.31 & -3.1 & -3.6 \\
$\mathrm{TiO}_{2}$ & +0.23 & -0.45 & -0.59 \\
$\mathrm{Al}_{2} \mathrm{O}_{3}$ & +0.063 & +0.21 & +0.42 \\
$\mathrm{~B}_{2} \mathrm{O}_{3}$ & -0.033 & -1.18 & -1.23 \\
\hline
\end{tabular}

Rather than utilize simple linear fittings to experimental data, the authors here have been employing a somewhat different approach; one that gives some access to glass design over wider compositional ranges and properties. For the parameters described thus far in this section, a modern form of the Winkelmann-Schott [63] addition model is used to calculate the refractive index (and other properties) of a mixture of glass materials, using volume fraction as the additivity parameter [64]. More specifically, the equation governing the mixture is given by

$$
G=\sum_{i} g_{i} x_{i}
$$

where $g$ is the bulk parameter of constituent $i, x$ is the additivity parameter (volume fraction in this case), and $G$ is the property of the aggregate glass.

For purposes of discussion, assume a binary glass mixture having constituents A and B, each possessing a bulk material value of $g$ (which are refractive index [65], mass density [66], and the inverse of the acoustic velocity [67]; a simple derivation can be found in [68]). The constituents are assumed to be well-mixed and that the glass structure does not change significantly across a desired compositional range. In other words, the binary system acts as a simple mixture across that compositional range. The volume fraction can be expressed in terms of the mass density, molar mass $(M)$, and the molar concentration $[C]_{\text {mole }}$ of each constituent as 


$$
x_{A}=\frac{\frac{M_{A}}{\rho_{A}}\left[C_{A}\right]_{\text {mole } \%}}{\frac{M_{A}}{\rho_{A}}\left[C_{A}\right]_{\text {mole } \%}+\frac{M_{B}}{\rho_{B}}\left[C_{B}\right]_{\text {mole } \%}},
$$

with $x_{B}=1-x_{A}$. The resulting calculation gives the property of the binary glass, ideally across the whole compositional range of $100 \%$ of constituent $\mathrm{A}$ to $100 \%$ of constituent $\mathrm{B}$. In the cases where the bulk values are not known, they can become empirical fitting parameters that, once found, can serve as a basis for extrapolation to a more optimized composition. As previously discussed, a summary of material properties obtained through these means can be found in [35]. Above-and-beyond what has been identified in [55], the work in [35] includes $\mathrm{Y}_{2} \mathrm{O}_{3}$ [69], $\mathrm{MgO}$ [33], $\mathrm{SrO}$ [70], $\mathrm{BaO}$ [71], $\mathrm{Yb}_{2} \mathrm{O}_{3}$ [72], $\mathrm{La}_{2} \mathrm{O}_{3}$ [73], $\mathrm{Lu}_{2} \mathrm{O}_{3}$ [74], and $\mathrm{Li}_{2} \mathrm{O}$ [34], providing a broad palette of dopant selection for glass design.

Interestingly, it is possible to deduce both the density and index of the bulk materials, so long as both are assumed for one of the constituents (usually for pure silica as the base material). To illustrate this, Figure 4 provides an example calculation for binary germanosilicate glass utilizing the parameters found in [75] (blue curve). When the mass density is modified for the same bulk refractive index value (these can be read from the endpoints on the graph), the curvatures of the graphs change, offering a means to obtain fittings for it with some degree of confidence. To clarify, Equation (15) does not necessarily give insight into the glass structure. Instead, it is a simple empirical model that can be used in the design of the glass comprising an optical fiber. Most importantly, it provides sufficient degrees-of-freedom to obtain very good fits to experimental data across wide compositional ranges. With caution, this enables simple extrapolations to compositions more suitable for a given application. The methodology has successfully been applied to $\mathrm{BaO}$ [71] and $\mathrm{Al}_{2} \mathrm{O}_{3}$ [76] silicates, but to the best of the authors' knowledge has not yet been used in germanosilicate glasses of varying mass density for a fixed composition (or, in other words, a varying bulk $\mathrm{GeO}_{2}$ mass density).

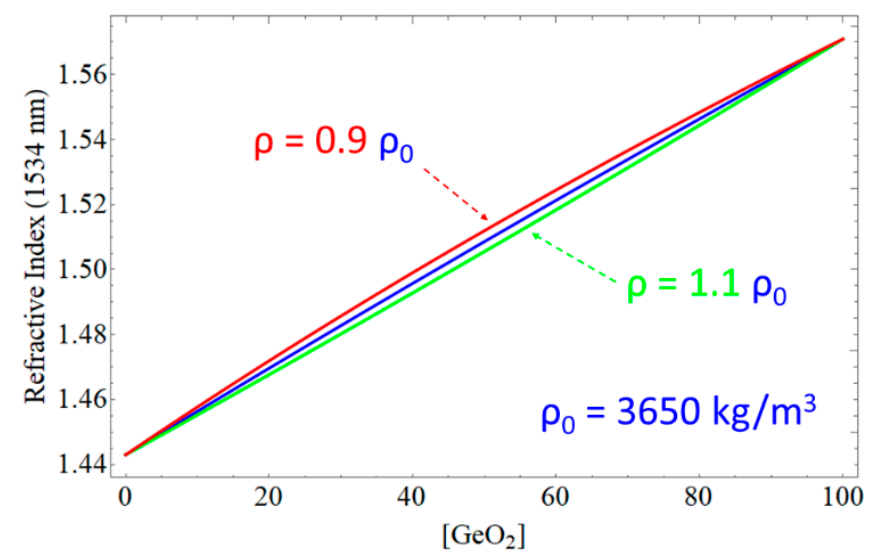

Figure 4. Simulated refractive index of binary germanosilicate as a function of the $\mathrm{GeO}_{2}$ concentration (in $\mathrm{mol} \%$ ) for a base density of $3650 \mathrm{~km} / \mathrm{m}^{3}$ (blue curve). The effect of raising or lowering the density in the model affects the curvature of the functions.

With regard to Figure 4, it is apparent that variations in the fiber processing/fabrication history, those that lead to differences in glass density, will give rise to fibers with different material characteristics. The same can be said of the properties of the individual glass constituents, including the $\mathrm{SiO}_{2}$ component in a multicomponent glass. However, as a simplification, the latter usually is assumed to have fixed properties in the additive model. It was shown [76] experimentally, in a binary aluminosilicate system, that a $25 \%$ increase in the density of the $\mathrm{Al}_{2} \mathrm{O}_{3}$ component gave rise to a $9 \%$ increase in $\mathrm{V}_{\mathrm{L}}$ and $5 \%$ increase in $\mathrm{n}$ (in both cases for the $\mathrm{Al}_{2} \mathrm{O}_{3}$ component). Regardless of some randomness associated with fabrication, it is not unreasonable to expect that the glass, in fiber form, would have properties not too dissimilar to those in bulk form. This comes with the caveat that fibers are rapidly quenched, whereas in many instances bulk glass samples are annealed, which can lead to some changes to the Brillouin scattering characteristics [77]. This is important to note, as the literature 
is replete with the elastic characterization of bulk glass (e.g., lithium and sodium silicates, with and without $\mathrm{Fe}_{2} \mathrm{O}_{3}[78,79]$, barium alkali silicate glasses [80], strontium manganese borate glasses [81], titanium silicate [82], alkali and alkaline earth metal aluminosilicates [83], and lead and zinc silicate glass [84] just to name a few). Given their very different thermal histories, this argument also can be extended to the case of preform versus drawn fiber. For example, alumina seems to act somewhat differently in going from preform [55] to fiber [76]. It already is well-known that variations in draw tension, temperature, etc. can also lead to frozen-in effects that may influence the refractive index [85] and acoustic velocity $[75,86]$. Thus, each of the design coefficients and equations provided above should be applied with some caution and care.

The modeling presented thus far allows one, in a straightforward way, to design a desired frequency distribution for the Brillouin scattering interaction. Another common computational approach is the finite element method (FEM). Several groups have used FEM for the design or analysis of the Brillouin scattering spectra in optical fiber [87-91]. One advantage is that these methods may offer greater computational efficiency for more complicated fiber structures, especially with the use of commercial software [91]. A drawback, however, especially with commercial software, is that they generally do not take into consideration those additional parameters that make up Equation (10). This may not be important if a fiber should be lightly doped and be comprised mainly of silica; $g_{B}$ will remain about the same. However, even a few $\mathrm{mol} \%$ of some additives can have a significant impact on $g_{B}$ (see, for example, the effect of $\mathrm{B}_{2} \mathrm{O}_{3}$ on $\Delta v_{B}$ [75]). Early on, Niklès et al. [57] observed a significantly broadening spectrum (and therefore decrease in $g_{B}$ ) with increasing $\mathrm{GeO}_{2}$ content. Indeed, this is true of all silicate additives listed in [35].

Continuing the discussion more broadly, several simulations, whether of the boundary-value [45] or FEM type, assume that the cladding acts as the predominant waveguide in an acoustically anti-guiding fiber [91]. More specifically, the interacting modes are those defined by the cladding-to-buffer boundary. There is value in scrutinizing this assumption since the phonon lifetime is on the order of $10 \mathrm{~ns}$ [49]. Given the speed of sound in pure silica (Equations (12) and (13)), the cladding is roughly two phonon lifetimes wide in a standard $125 \mu \mathrm{m}$ fiber. It is, therefore, not clear what role the cladding boundary does play in acoustically anti-guiding fiber in the case of small or intermediate cladding diameters. This, likely, is very little in the large fibers encountered in high-power lasers [92] (a $400 \mu \mathrm{m}$ cladding diameter gives about 6 phonon lifetimes). While acoustically guiding fibers may be preferable in Brillouin-based distributed sensors, hopefully the preceding discussion is still important, as it sheds more light on the contributions to $\Delta v_{B}$. To conclude, it has been shown that, for an acoustic mode occupying regions of the fiber with differing material $\Delta v_{B}$, both FEM and boundary value computational methods can be used to determine a modal value $[93,94]$ spectral width.

Attention now is turned towards the other materials parameters in Equation (10). First, the material acoustic velocity, refractive index, and mass density usually are set by the design of the waveguide. All likely will be within $10 \%$ of that of silica, with the refractive index difference probably much less than that for a single mode, weakly guiding, optical fiber. The photoelastic constant, $\mathrm{p}_{12}$, remains and is doubly interesting since: (1) it can take on either positive or negative values [95]; and (2) $g_{B}$ is proportional to the square of its value. It turns out that the common dopants, $\mathrm{GeO}_{2}$ [96], $\mathrm{B}_{2} \mathrm{O}_{3}$ [96], and $\mathrm{P}_{2} \mathrm{O}_{5}$ [97] all have photoelastic constants that are comparable to that of $\mathrm{SiO}_{2}$, with that of $\mathrm{B}_{2} \mathrm{O}_{3}$ apparently slightly higher [96]. However, other dopants that have been applied, such as $\mathrm{Al}_{2} \mathrm{O}_{3}$ [52], possess a negative-valued $p_{12}$. This leads to a reduction in $\mathrm{p}_{12}$ when added to silica, and coupled with any spectral broadening, this can significantly offset $g_{B}$. It should be noted that $p_{12}$ does not affect $\Delta v_{B}$.

Therefore, in some fiber designs, perhaps where absolute or relative Brillouin gain is important, consideration of the material in the simulation of the BGS is essential. Complete sets of materials models derived from Equation (15) are provided in the paper sequence in $[35,98-100]$ (and are not repeated here). Although the focus was on the suppression of nonlinearities, generally, they also may be applied to the calculation of $g_{B}$ for sensing applications. As can be inferred from Table 1 in [35], 
however, it will be a challenge to start with pure silica and, then through a materials route, enhance $g_{B}$. Stated another way, adding just about anything to $\mathrm{SiO}_{2}$ will lower its material $g_{B}$. This is not meant to discourage investigations into these areas for Brillouin-based distributed sensors, since it is the response of the material to the thermo-mechanical environment that is most important. Fortunately, some interesting cases require displacing only lesser amounts of silica, such that $g_{B}$ is not decreased to a value below system feasibility, should this be a design concern.

To conclude the discussion of $g_{B}$, an example calculation is presented. Binary $\mathrm{P}_{2} \mathrm{O}_{5}$ in $\mathrm{SiO}_{2}$ is the selected material system. This is of interest since $\mathrm{P}_{2} \mathrm{O}_{5}$ has a negative thermo-optic coefficient that can give rise to fibers whose $v_{B}$ are immune to changes in temperature [94]. Table 3 provides a summary of the numbers utilized in the calculation. The refractive index values are those at 1534 $\mathrm{nm}$, and the remaining data are from [94,97]. The spectral width is listed at a reference frequency of $11 \mathrm{GHz}$ (arbitrarily selected). This is important since, as the $\mathrm{P}_{2} \mathrm{O}_{5}$ content changes, so does $\Delta v_{B}$. This results from the fact that the addition of $\mathrm{P}_{2} \mathrm{O}_{5}$ decreases the acoustic velocity, and since the acoustic wavelength is fixed to the optical wavelength via the Bragg condition, the frequency also decreases. Most materials have a spectral width that typically is proportional to the square of the acoustic frequency [101], though this is suggested not to be the case for $\mathrm{B}_{2} \mathrm{O}_{3}$ [102] (more on this topic below). Referring to Figure $5, g_{B}$ initially drops from that of pure $\mathrm{SiO}_{2}$ due to the large, relative acoustic attenuation (large $\Delta v_{B}$ ) coefficient brought by $\mathrm{P}_{2} \mathrm{O}_{5}$. However, as the $\mathrm{P}_{2} \mathrm{O}_{5}$ concentration increases, and the acoustic velocity value decreases (decreasing $\left.v_{B}\right), \Delta v_{B}$ ultimately narrows to a point where that effect dominates, raising $g_{B}$. This results in the absolute minimum in $g_{B}\left(\left[\mathrm{P}_{2} \mathrm{O}_{5}\right]\right)$ in Figure 5 . In the case of materials with negative $p_{12}$, such as alumina, a singular binary silicate composition where $g_{B}=0$ is encountered [103]. What is more, materials that raise the acoustic velocity result in an increasing (not decreasing) spectral width with increasing concentration.

Table 3. Material properties used to calculate $g_{B}$ for the binary phosphosilicate glass.

\begin{tabular}{cccccc}
\hline & $n$ & $V_{\boldsymbol{L}}(\mathbf{m} / \mathbf{s})$ & $\rho\left(\mathbf{k g} / \mathbf{m}^{\mathbf{3}}\right)$ & $p_{\mathbf{1 2}}$ & $\Delta \boldsymbol{v}_{\boldsymbol{B}}(\mathbf{M H z} @ \mathbf{1 1} \mathbf{~ G H z})$ \\
\hline $\mathrm{SiO}_{2}$ & 1.444 & 5970 & 2204 & 0.252 & 17.0 \\
$\mathrm{P}_{2} \mathrm{O}_{5}$ & 1.488 & 3936 & 2390 & 0.226 & 176.8 \\
\hline
\end{tabular}

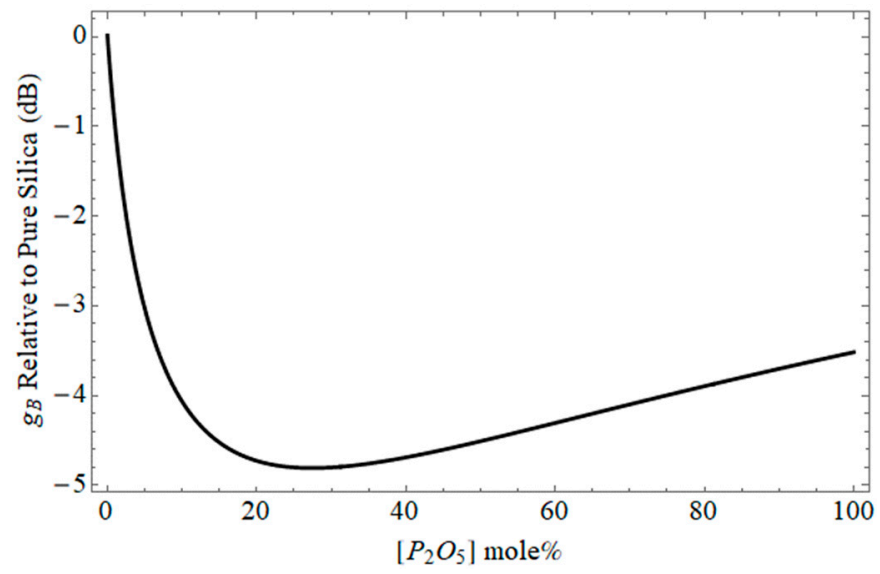

Figure 5. $g_{B}$ for the binary phosphosilicate glass as a function of $\mathrm{mol} \%$ of $\mathrm{P}_{2} \mathrm{O}_{5}$ relative to that of pure $\mathrm{SiO}_{2}$ in units of $\mathrm{dB}$. An absolute minimum is observed in the plot. Even a few mol \% of $\mathrm{P}_{2} \mathrm{O}_{5}$ can cause a significant drop in $g_{B}$.

Turning now to the thermo-mechanical response, the Bragg condition may be rewritten in terms of the acoustic velocity as

$$
v_{B}=\frac{2 n_{e f f} V_{a}}{\lambda_{o}}
$$


where the index is the effective index of the optical mode, and $V_{a}$ is the acoustic mode velocity. If the fiber undergoes strain $(\varepsilon)$ or a change in temperature $(T)$, the fiber response may be found by differentiating Equation (17), giving rise to

$$
\frac{d \nu_{B}}{d(T, \varepsilon)}=\frac{2}{\lambda_{o}}\left(V_{a} \frac{d n_{e f f}}{d(T, \varepsilon)}+n_{e f f} \frac{d V_{a}}{d(T, \varepsilon)}\right) .
$$

The values for pure silica (bulk material, not waveguide) are summarized in Table 4 . The expression for $\mathrm{d} n / \mathrm{d} \varepsilon$ depends upon the unstrained index, $n_{0}$. At a wavelength of $1534 \mathrm{~nm}$, the index is 1.444 [50], so this term is $0.262 \varepsilon^{-1}$. Evaluating the responses at said wavelength using the parameters provided previously and in Table 4 gives $\mathrm{d} v_{B} / \mathrm{d} T=1.13 \mathrm{MHz} / \mathrm{K}$ and $\mathrm{d} v_{B} / \mathrm{d} \varepsilon=57.1 \mathrm{GHz} / \varepsilon$ (the thermal and strain coefficients, respectively). In the case of pure silica, the term possessing the derivative of $V_{a}$ is more than one order of magnitude larger than the other. Regardless, the advantage of utilizing shorter optical wavelengths is obvious. As a quick note on $\mathrm{d} n / \mathrm{d} T$, Prod'homme [104] argued that $\mathrm{d} n / \mathrm{d} T$ encompasses two competing processes: (a) a decrease in density associated with thermal expansion, resulting in a decreased refractive index; and (b) an increase in polarizability as the electrons become more loosely bound to their nuclei, thus increasing the refractive index. If the latter process dominates, then $\mathrm{d} n / \mathrm{d} T$ is positive. A list of $\mathrm{d} n / \mathrm{d} T$ for numerous silica additives can be found in [35], but, in short, $\mathrm{F}, \mathrm{B}_{2} \mathrm{O}_{3}, \mathrm{P}_{2} \mathrm{O}_{5}$, and $\mathrm{SrO}$ have been shown to bring negative values of $\mathrm{d} n / \mathrm{d} T$ to the mixture.

Table 4. Material response to changes in $\mathrm{T}$ and $\varepsilon$ for pure glass $\mathrm{SiO}_{2}$.

\begin{tabular}{cc}
\hline Parameter & Value \\
\hline $\mathrm{d} n / \mathrm{d} T\left(10^{-6} \mathrm{~K}^{-1}\right)$ & $+10.42[94]$ \\
$\mathrm{d} V_{a} / \mathrm{d} T(\mathrm{~m} / \mathrm{s} / \mathrm{K})$ & $+0.555[94]$ \\
$\mathrm{d} n / \mathrm{d} \varepsilon(1 / \varepsilon)$ & $-\left(n_{0}^{3} / 2\right) \times 0.174[52]$ \\
$\mathrm{d} V_{a} / \mathrm{d} \varepsilon(\mathrm{m} / \mathrm{s} / \varepsilon)$ & $+29,240[97]$ \\
\hline
\end{tabular}

These response values are typical of those found in the literature for optical fiber with conventional coatings [105]. Deviation from them depends on the absolute fiber configuration, coating, and glass composition. For instance, it has been shown $[106,107]$ that one can enhance the thermal sensitivity with a coating of high coefficient of thermal expansion (CTE). Going in the other direction, a reversal of the sign of the thermal response was demonstrated by using a high-CTE core cladded in low-CTE silica [34]. As discussed below, these possibilities stem from silica's anomalous behavior of decreasing acoustic velocity with increasing applied pressure (compression) [108-110] (this is the leading reason why $v_{\mathrm{B}}$ increases with applied strain).

The glass composition also plays a primary role in the magnitude and sign of the response coefficients. Niklès et al. [57] showed that the addition of $\mathrm{GeO}_{2}$ to silica decreases the magnitude of the thermal coefficient. Interestingly, the addition of $\mathrm{Al}_{2} \mathrm{O}_{3}$ [52], $\mathrm{SrO}$ [70], $\mathrm{BaO}$ [71], $\mathrm{La}_{2} \mathrm{O}_{3}$ [73], and $\mathrm{Lu}_{2} \mathrm{O}_{3}$ [74] were all found to reduce the magnitudes of both the thermal and strain coefficients. This is interesting from the perspective of designing a fiber whose response to temperature changes or strain is zero.

Niklès et al. [57] also showed that the Brillouin spectral width decreases with increasing temperature in germanosilicate optical fiber. This was attributed to acoustic absorption in the tails of the thermo-absorption curve. Since the acoustic attenuation (damping, or also $\Delta v_{B}$ ) has a peak at cryogenic temperatures (just over $100 \mathrm{~K}$ at $27.5 \mathrm{GHz}$ hypersonic frequency using $633 \mathrm{~nm}$ optical illumination, see Figure 6) [111], the Brillouin spectral width must then be decreasing in value moving away from this peak (increasing temperature). Interestingly, being far from the peak also gives rise to the frequency- (or inverse-wavelength-) squared dependence of $\Delta v_{B}$. More specifically, the Brillouin spectral width can be expressed as [112] 


$$
\Delta v_{B}=\left(\frac{2 n}{\lambda_{o}}\right)^{2} \frac{\eta^{\prime}(v)}{\rho}
$$

where $\eta^{\prime}(v)$ is a dynamic viscosity. Through an analysis utilizing the theory in [112], Law et al. [102] showed that when the temperature is far from the peak of the thermo-absorption curve, $\eta^{\prime}(v)$ becomes independent of frequency. However, in some materials, they suggested, where the fiber fictive temperature is near such a peak, $\Delta v_{B}$ acquires a sub-quadratic dependence on frequency, resulting from the frequency dependence of $\eta^{\prime}(v)$. As also is apparent, the relative shape (magnitude and peak temperature) of these thermo-absorption curves must give rise to the relative contribution to $\Delta v_{B}$ by dopants [57], as would seem to be confirmed with the case of $\mathrm{GeO}_{2}$ [113]. For completeness, a simulation of $\Delta v_{B}$ (after [111,112]) as a function of temperature is shown in Figure 6.

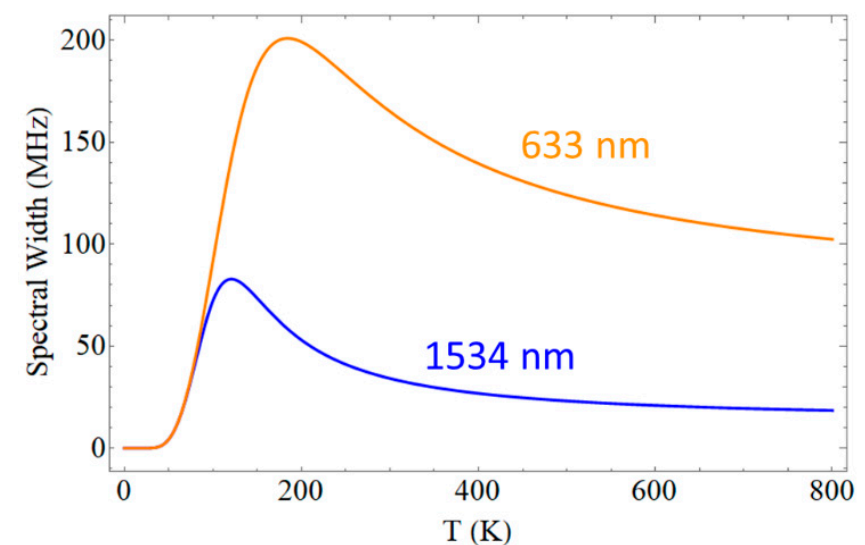

Figure 6. Brillouin spectral width simulation for pure silica at wavelengths of $633 \mathrm{~nm}$ and $1534 \mathrm{~nm}$. Far from the peak, the spectral width is proportional to $v_{B}{ }^{2}$. The spectral width is proportional to the acoustic attenuation coefficient.

Each of the parameters presented above has some dependence upon the temperature of the optical fiber. From the perspective of the waveguide, as the refractive index or acoustic velocity changes with $T$, so can guiding characteristics that influence $\Gamma_{m}$ (though likely in an insignificant way). From a material perspective, as the fiber heats, the acoustic velocity changes, thereby resulting in a change in $v_{B}$. This, in turn, results in a change in $\Delta v_{B}$ and therefore $g_{B}$. The spectral width is also a function of $\mathrm{T}$ as discussed in the preceding paragraph. Parker et al. [114] provided an expression for scattered Brillouin power as

$$
P_{B}=\frac{A T}{v_{B}^{2}}
$$

where $A$ is an empirical calibration constant associated with the fiber being used in a system. As discussed below, the power dependence on $T$ has been used as an additional tool in discriminating $T$ from $\varepsilon$ in a distributed system $[115,116]$.

\section{Fiber Configurations}

The previous two sections, with references (and the theoretical and empirical findings found therein), provided summaries of the waveguide and material properties that are used in discussing several novel Brillouin-tailored fibers that can be found in the literature. As a sensing tool, one logically can conclude that both the thermo-mechanical response and scattering efficiency of the Brillouin process are of primary interest. For instance, a fiber with enhanced $g_{B}$ may be desirable for short- to moderate-reach sensors with high SNR. However, as discussed above, this may prove to be challenging since fused silica, among oxide compounds, has a relatively high $g_{B}$ due to a narrow $\Delta v_{B}$ coupled with a relatively large $\mathrm{p}_{12}$. 
In terms of the thermo-mechanical response, a deployed optical fiber will be subject to changes in both $\mathrm{T}$ and $\varepsilon$. Obviously, then, if one could somehow devise a configuration whereby a system of two equations with two unknowns ( $T$ and $\varepsilon$ ) can be formulated, then simultaneous strain and temperature sensing could be achieved. For instance, consider the simultaneous use of two independent fibers [117]. Further, consider that each has a unique thermal and strain coefficient. In this case, the system can be characterized by the matrix equation

$$
\left[\begin{array}{l}
\Delta v_{B 1} \\
\Delta v_{B 2}
\end{array}\right]=\left[\begin{array}{ll}
C_{T 1} & C_{\varepsilon 1} \\
C_{T 2} & C_{\varepsilon 2}
\end{array}\right]\left[\begin{array}{c}
\Delta T \\
\Delta \varepsilon
\end{array}\right]
$$

where the Cs represent the two thermal and strain coefficients in the obvious way. Equation (21) describes the change in the $\nu_{\mathrm{B}}$ 's with changes in $T$ or $\varepsilon$. Therefore, knowing the $C s$ a priori, distributed measurements of frequency on the two fibers gives $T$ and $\varepsilon$ from some starting, relaxed state (by solving the inverse-matrix problem). As an aside, Equation (21) need not be limited to a $2 \times 2$ matrix and can include other (even non-Brillouin) parameters, such as Brillouin power (as discussed at the end of the previous section). Other examples include simultaneous use of Brillouin scattering and changes in birefringence in a polarization-maintaining fiber [118-120], and the use of Brillouin scattering coupled with thermally-induced changes to the emission spectrum of Er doped into the fiber [121]. The Cs should differ significantly enough to achieve any required system sensitivity. For example, Bao et al. [117] utilized a second fiber that could be kept loose such that no strain was experienced by that fiber. In this case, $C_{\varepsilon 2}=0 \mathrm{GHz} / \varepsilon$ and $C_{\varepsilon 1}$ could remain similar in magnitude to that of silica.

The two fibers (or rather their cores) need not be part of independent structures. For example, $\mathrm{Li}$ et al. proposed a dual-core fiber for discriminative sensing [122] and detailed experimental validation was recently provided [123]. In this case, the two cores have non-overlapping values of $v_{B}$ and have differing thermal and strain coefficients. Mizuno et al. [124] described the use of multi- (7-) core fiber for the distributed Brillouin sensing application, but only characterized two of the cores for said application. They found that the thermal and strain coefficients differed by $<10 \%$ in the first and second cores, but with one parameter being larger and the other being smaller in the first core. They suggested that the change in coefficients largely can be attributed to practical differences in the core materials. Zhao et al. $[125,126]$ showed that the Brillouin scattering response of multi-core fibers is highly sensitive to bending, thus paving the way for three-dimensional shape sensors.

Equation (21) need not be limited to the use of two or more optical fibers/cores. Coefficients 1 and 2 instead may refer to two distinct optical modes in a fiber (if the fiber is multimode) [127]. Should the thermal and strain responses of Brillouin scattering involving two orthogonal optical modes differ, they also may be utilized for discriminative sensing. To remind the reader, the result, or consequence, of the thermo-mechanical response is carried by the scattered optical mode via an interaction with the guided (or possibly anti-guided) acoustic wave. Both the optical and acoustic properties of the fiber may be functions of the environment, though, as discussed above, the latter dominates in fibers comprised mainly of silica. Weng et al. [128] showed that the acousto-optic interactions in such fibers involve optical and acoustic modes that have the most similar shape, and therefore, as would be expected, largest spatial overlap (see Equation (8)). Very nice theoretical analyses of such interactions can be found in $[129,130]$. Xu et al. [62,131] provided an analysis involving modes possessing orbital angular momentum, while Wu et al. [132] described a hybrid Raman-Brillouin system in a few-mode fiber.

Another possibility for discriminative sensing is the use of multiple acoustic mode interactions (or "peaks" in the BGS) in an optically single mode fiber, as first suggested by Lee et al. [133]. In this case, both the fiber's acoustic velocity and refractive index profiles are tailored to enhance the gain on one or more HOAMs. Differences in the sensitivity coefficients between the various modes arise from variations in their spatial overlaps with the compositional profile. Figure 7 provides such a BGS (though fictitious) modified utilizing these procedures. The fundamental $\left(\mathrm{L}_{01}\right)$ and one HOAM (such as $\mathrm{L}_{03}$ ) now have similar strength, and their responses to a change in $\mathrm{T}$ or $\varepsilon$ differ. In this case, the 
HOAM may have greater overlap with a region containing a dopant that lowers $C_{T}$ or $C_{\varepsilon}$, since, as described above, these coefficients can be strong functions of the material. A potential drawback to this approach is that it lowers the gain on the $\mathrm{LP}_{01}-\mathrm{L}_{01}$ acousto-optic interaction. However, it has been suggested $[134,135]$ that this could be advantageous in long systems due to the elevated threshold for the onset of the stimulated form of Brillouin scattering (SBS). In Refs. [133,134], Corning LEAF fiber was utilized for discriminative sensing due to the presence of multiple acoustic mode interactions of reasonably similar magnitude.

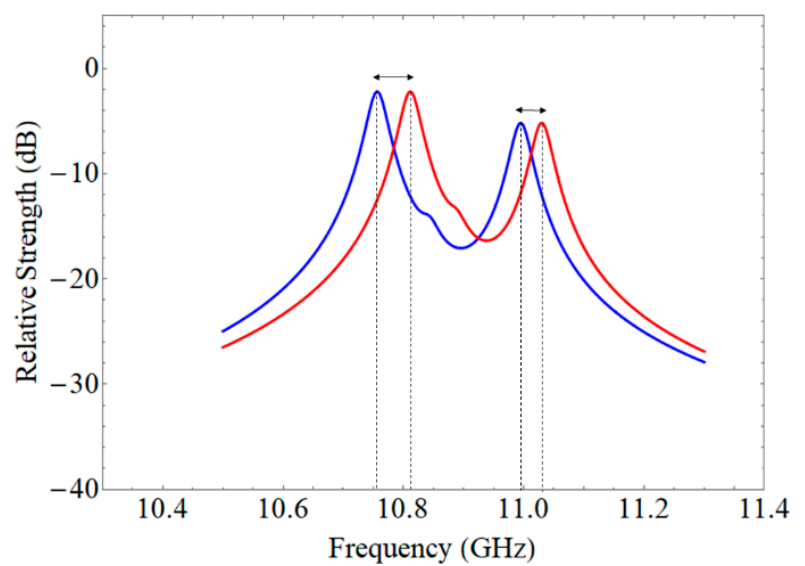

Figure 7. Example of a BGS tailored to have two acoustic mode interactions of similar strength. The responses of the modes to changes in $T$ or $\varepsilon$ differ. This illustration may represent a typical fiber whose temperature or applied strain has been increased in going from the blue to the red curve.

Along the aforementioned design approach, Zou et al. [136,137] described a fiber with a $\mathrm{GeO}_{2}$-doped core and F-doped inner cladding whereby such differences in material properties led to different thermal and strain coefficients for each guided acoustic mode. They also demonstrated enhancement of the strength of the interaction with the highly oscillatory $\mathrm{L}_{03}$ mode. In a theoretical study, Dragic [138] suggested decoupling the optical and acoustic boundaries to achieve gain equalization between the fundamental mode $\left(\mathrm{L}_{01}\right)$ and a HOAM. A diagram of such a scheme is provided in Figure 8. Law et al. [94,97] demonstrated a simple means of calculating the thermal and strain coefficients for the interactions with the HOAMs in a radially non-uniform $\mathrm{P}_{2} \mathrm{O}_{5}$-doped fiber with matched inner cladding, with excellent agreement between theory and experiment. Note that a revised $\mathrm{d} n / \mathrm{d} T$ for $\mathrm{P}_{2} \mathrm{O}_{5}$ in silica was recently suggested [139]. Additional papers on tailoring the acoustic mode distribution can be found in Refs. [44,61,87,140-142]. Finally, Lu et al. [143] used three acoustic modes in LEAF and the relative intensity of two resulting beat signals in the several hundred $\mathrm{MHz}$ range for discriminative sensing. To conclude, these fiber configurations are enabled by the relatively wide range of materials and their respective influences on the Brillouin scattering characteristic (see Table 2 or [35]).

As an interesting side note, the aforementioned methods to tailor the BGS require transverse (radial and possibly azimuthal) engineering of the optical and acoustic waveguide properties. However, an optical fiber also may be tailored in the axial direction. Indeed, this has been a known method to suppress SBS in optical fibers: by varying the composition or waveguide properties along the fiber length, the BGS becomes distributed across a wider range of frequencies [144-146], thereby decreasing the peak value of $g_{B}$. Such a fiber enables the possibility of having a unique one-to-one mapping of some position along the length of fiber to a frequency on the BGS. It was suggested [147] that such a fiber can be used for simple distributed sensing in that a modest continuous-wave (CW) measurement of the BGS of the entire fiber can give thermal or strain distributions along the axial direction of that fiber.

Rather than obtaining full discriminative details about the fiber's environment, perhaps in some cases only a single parameter is wanted, such as a local $\varepsilon$ or $\mathrm{T}$ alone. It may then be impactful to 
devise a fiber that is immune to changes in $T$ or $\varepsilon$, respectively. These are referred to as "athermal" and "atensic" (after [71]), respectively. As discussed in the previous section, it appears that the community has yet to observe an increase in $C_{T}$ or $C_{\varepsilon}$ simply by adding dopants to silica. In other words, adding just about any oxide to the silica core will reduce the thermal or strain sensitivity. However, on the bright side, this represents a possible path to athermal or atensic fibers.



Figure 8. Example acoustic and refractive index profiles for the equalization of Brillouin gain between the $\mathrm{L}_{01}$ and higher order acoustic modes. In this configuration, the optical and acoustic boundaries are decoupled [138].

One drawback to this approach, however, in many of the silicate systems studied (e.g., SrO [70], $\mathrm{BaO}$ [71], $\mathrm{La}_{2} \mathrm{O}_{3}$ [73], and $\mathrm{Lu}_{2} \mathrm{O}_{3}$ [74]), is that an athermal (or atensic) fiber composition usually is accompanied by a significant reduction in its sensitivity to strain (or temperature) and in $g_{B}$. An exception was observed in [34] with the addition of $\mathrm{Li}_{2} \mathrm{O}$ to silica, wherein an athermal fiber composition (that also is optically single mode) could be achieved with a strain sensitivity similar to that of pure silica. As discussed in the previous section, this was attributed to a significant increase in the CTE of the core relative to the cladding with the addition of lithia. A possible drawback to this structure was that it was acoustically anti-guiding with a wide $\Delta v_{B}$. It was suggested that this could be avoided with the use of $\mathrm{Na}_{2} \mathrm{O}$ or $\mathrm{K}_{2} \mathrm{O}$. Interestingly, the results in [34] were extrapolated to higher $\mathrm{Li}_{2} \mathrm{O}$ concentrations [148] and modeling results suggest a maximum (magnitude) thermal response in the range of $-6.5 \mathrm{MHz} / \mathrm{K}$, roughly six times higher than silica (but negative), exists in the lithium silicate system; a value comparable to that in polymer fibers [149].

The effect of CTE mismatch between core and cladding also was studied in the aluminosilicate system in $[150,151]$ and the conclusion seems to be that in a fiber where the core CTE (once again, by adding just about anything to silica, etc.) is greater than that of the cladding (assumed to be pure silica), $\varepsilon$ also is a function of T. Note that a new model for the CTE using Equation (15) can be found in [152]. However, this dependence may be weak, depending on the absolute composition (which and in what quantity dopants are used). This results from a positive pressure forming on the $\mathrm{SiO}_{2}$ component of the core glass as the temperature is increased. Similarly, and as discussed previously, the fiber could be coated in a material that strains the silica as the temperature is increased and thereby enhancing the thermal sensitivity $[106,107]$.

\section{Conclusions}

Specialty optical fibers for the Brillouin-scattering-based distributed sensor application were briefly reviewed. While most may not consider Corning's LEAF non-zero dispersion shifted fiber to be a "specialty fiber", its use in certain distributed sensor configurations lies well outside the reasons for its development. Therefore, it has been included in this discussion, but with the consideration that acoustic waveguide design could further be optimized and developed for distributed sensors. The 
optical and acoustic waveguide properties of silicate glass optical fibers first were discussed. Next, material properties were described in the context of how they modify the relevant Brillouin scattering attributes of the fiber. Finally, the literature was surveyed for fiber configurations that give rise to novel methods and arrangements for this distributed sensing application. It has been suggested that these fibers enable systems capable of discriminative sensing (for example, distinguishing changes in $\varepsilon$ and T), 3-D shape sensing, simple frequency-domain sensing, systems that are immune to changes in one or more environmental conditions (such as with athermal or atensic fibers), and fibers with enhanced thermo-mechanical response.

Acoustic waveguide design, while leading to novel fiber configurations, such as a multi-peaked BGS with potential for discriminative sensing, has been limited to a few common dopants developed for conventional fabrication methods (such as modified chemical vapor deposition (MCVD)), namely $\mathrm{GeO}_{2}, \mathrm{Al}_{2} \mathrm{O}_{3}$, and $\mathrm{F}$. This has limited the range of fiber properties that are feasible or even possible. As such, the design of the BGS, the relative strength of $g_{B}$, and thermal and strain coefficients are limited to a narrow range with the use of these dopants. The use of less conventional materials, even in the silicates, can enrichen the set of tools that can be used in the design of such optical fibers. For instance, the use of less conventional materials such as alkali metal oxide dopants can lead to fibers immune, or even several times more sensitive, to changes in temperature. Such materials also can find value in multi-core fibers and multi-material fibers [153], especially for high-sensitivity discriminative, multivariable sensing.

However, due to technological limitations related to the material in an entrenched fabrication process, such new glass systems have not widely been studied utilizing the more conventional fabrication methods found in the commercial sector [154]. For instance, many of the novel silicate systems studied by these authors were fabricated using the molten core process (more details can be found in [155]) which differs significantly from the MCVD process in terms of both thermal and processing history, and ranges of compositions that can be produced. Although not currently commercially pervasive, it is the contention of these authors that the maturation of this and other fiber and glass fabrication methods [156-158] can give access to a wider range of the Periodic Table and fiber embodiments, and more widely-varied thermo-mechanical responses. This can lead to simpler and less expensive sensing systems (such as through beat signal measurements found in [44,143], bringing the measurement frequency to a potentially more cost-effective region in the RF [159]). While fiber development cost may initially be high, the long-term payoff could be economies of scale.

Author Contributions: Conceptualization, P.D. and J.B.; Investigation, P.D. and J.B.; Writing-Original Draft Preparation, P.D. and J.B.; Writing-Review \& Editing, P.D. and J.B.; Funding Acquisition, P.D. and J.B.

Funding: The Authors gratefully acknowledge the financial support from the Directed Energy Joint Transition Office (DE JTO) through sustained support over many years including contracts: W911NF-05-1-0517, FA9550-07-1-0566, W911NF-12-1-0602, FA9451-15-D-0009/0001 and 0002, and N00014-17-1-2546. Authors also gratefully acknowledge the Air Force Office of Scientific Research (AFOSR) and contract FA9550-16-1-0383.

Conflicts of Interest: The authors declare no conflict of interest.

\section{References}

1. Bao, X.; Chen, L. Recent Progress in Distributed Fiber Optic Sensors. Sensors 2012, 12, 8601-8639. [CrossRef] [PubMed]

2. Photonic Sensor Consortium Market Survey Report. 2018 Distributed and Single Point Fiber Optic Sensing Systems Forecast; Information Gatekeepers, Inc.: Winchester, UK, May 2018.

3. Iribas, H.; Urricelqui, J.; Mariñelarena, J.; Sagues, M.; Loayssa, A. Cost-Effective Brillouin Optical Time-Domain Analysis Sensor Using a Single Optical Source and Passive Optical Filtering. J. Sens. 2016, 7, 8243269. [CrossRef]

4. Mizuno, Y.; Zou, W.; He, Z.; Hotate, K. Proposal of Brillouin optical correlation-domain reflectometry (BOCDR). Opt. Express 2008, 16, 12148-12153. [CrossRef] [PubMed] 
5. Hayashi, N.; Mizuno, Y.; Nakamura, K. Simplified Configuration of Brillouin Optical Correlation-Domain Reflectometry. IEEE Photonics J. 2014, 6, 6802807I. [CrossRef]

6. Horiguchi, T.; Shimizu, K.; Kurashima, T.; Tateda, M.; Koyamada, Y. Development of a Distributed Sensing Technique Using Brillouin Scattering. J. Lightwave Technol. 1995, 13, 1296-1302. [CrossRef]

7. Lee, B. Review of the present status of optical fiber sensors. Opt. Fiber Technol. 2003, 9, 57-79. [CrossRef]

8. Ukil, A.; Braendle, H.; Krippner, P. Distributed Temperature Sensing: Review of Technology and Applications. IEEE Sens. J. 2012, 12, 885-892. [CrossRef]

9. Bao, X.; Chen, L. Recent Progress in Brillouin Scattering Based Fiber Sensors. Sensors 2011, 11, $4152-4187$. [CrossRef] [PubMed]

10. Thévenaz, L. Brillouin distributed time-domain sensing in optical fibers: State of the art and perspectives. Front. Optoelectron. China 2010, 3, 13-21. [CrossRef]

11. Barrias, A.; Casas, J.R.; Villalba, S. A Review of Distributed Optical Fiber Sensors for Civil Engineering Applications. Sensors 2016, 16, 748. [CrossRef] [PubMed]

12. Grattan, K.T.V.; Sun, T. Fiber optic sensor technology: An overview. Sens. Actuators A 2000, 82, 40-61. [CrossRef]

13. Galindez-Jamioy, C.A.; López-Higuera, J.M. Brillouin Distributed Fiber Sensors: An Overview and Applications. J. Sens. 2012, 2012, 204121. [CrossRef]

14. Selker, J.S.; Thévenaz, L.; Hurwald, H.; Mallet, A.; Luxemburg, W.; van de Giesen, N.; Stejskal, M.; Zeman, J.; Westhoff, M.; Parlange, M.B. Distributed fiber-optic temperature sensing for hydrologic systems. Water Resour. Res. 2006, 42, W12203. [CrossRef]

15. Motil, A.; Bergman, A.; Tur, M. State of the art of Brillouin fiber-optic distributed sensing. Opt. Laser Technol. 2016, 78, 81-103. [CrossRef]

16. Beugnot, J.-C.; Sylvestre, T.; Alasia, D.; Maillotte, H.; Laude, V.; Monteville, A.; Provino, L.; Traynor, N.; Mafang, S.F.; Thévenaz, L. Complete experimental characterization of stimulated Brillouin scattering in photonic crystal fiber. Opt. Express 2007, 15, 15517-15522. [CrossRef] [PubMed]

17. Zou, L.; Bao, X.; Chen, L. Brillouin scattering spectrum in photonic crystal fiber with a partially germanium-doped core. Opt. Lett. 2003, 28, 2022-2024. [CrossRef] [PubMed]

18. McElhenny, J.E.; Pattnaik, R.K.; Toulouse, J.; Saitoh, K.; Koshiba, M. Uniqu characteristic features of stimulated Brillouin scattering in small-core photonic crystal fibers. J. Opt. Soc. Am. B 2008, 25, 582-593. [CrossRef]

19. Dong, Y.; Bao, X.; Chen, L. Distributed temperature sensing based on birefringence effect on transient Brillouin grating in a polarization-maintaining photonic crystal fiber. Opt. Lett. 2009, 34, 2590-2592. [CrossRef] [PubMed]

20. Zou, L.; Bao, X.; Afshar, V.S.; Chen, L. Dependence of the Brillouin frequency shift on strain and temperature in a photonic crystal fiber. Opt. Lett. 2004, 29, 1485-1487. [CrossRef] [PubMed]

21. Lee, Y.W.; Urbanek, K.E.; Digonnet, M.J.F.; Byer, R.L.; Jiang, S. Measurement of the stimulated Brillouin scattering gain coefficient of a phosphate fiber. Proc. SPIE 2007, 6469, 64690L. [CrossRef]

22. Qin, G.; Sotobayashi, H.; Tsuchiya, M.; Mori, A.; Suzuki, T.; Ohishi, Y. Stimulated Brillouin Scattering in a Single-Mode Tellurite Fiber for Amplification, Lasing, and Slow Light Generation. J. Lightwave Technol. 2008, 26, 492-498. [CrossRef]

23. Lambin-Iezzi, V.; Loranger, S.; Saad, M.; Kashyap, R. Stimulated Brillouin scattering in SM ZBLAN fiber. J. Non-Cryst. Solids 2013, 359, 65-68. [CrossRef]

24. Abedin, K.S. Observation of strong stimulated Brillouin scattering in single-mode $\mathrm{As}_{2} \mathrm{Se}_{3}$ chalcogenide fiber. Opt. Express 2005, 13, 10266-10271. [CrossRef] [PubMed]

25. Bashkansky, M.; Dutton, Z.; Sanghera, J.; Pureza, P.; Aggarwal, I. Stimulated Brillouin scattering in single-mode $\mathrm{As}_{2} \mathrm{~S}_{3}$ and $\mathrm{As}_{2} \mathrm{Se}_{3}$ chalcogenide fibers. Opt. Express 2006, 14, 12063-12070.

26. Ballato, J.; Dragic, P. Glass: The Carrier of Light-A Brief History of Optical Fiber. Int. J. Appl. Glass Sci. 2016, 7, 413-422. [CrossRef]

27. Gloge, D. Dispersion in Weakly Guiding Fibers. Appl. Opt. 1971, 10, 2442-2445. [CrossRef] [PubMed]

28. Tamura, Y.; Sakuma, H.; Morita, K.; Suzuki, M.; Yamamoto, Y.; Shimada, K.; Honma, Y.; Sohma, K.; Fujii, T.; Hasegawa, T. The First 0.14-dB/km Loss Optical Fiber and its Impact on Submarine Transmission. J. Lightwave Technol. 2018, 36, 44-49. [CrossRef]

29. Kao, K.C.; Hockham, G.A. Dielectric-fibre surface waveguides for optical frequencies. Proc. Inst. Electr. Eng. 1966, 113, 1151-1158. [CrossRef]

30. Snitzer, E. Cylindrical Dielectric Waveguide Modes. J. Opt. Soc. Am. 1961, 51, 491-498. [CrossRef] 
31. Herstrøm, S.; Grüner-Nielsen, L.; Pálsdóttir, B. Acoustic index of Ge-doped optical fibers. Opt. Lett. 2009, 34, 3689-3691. [CrossRef] [PubMed]

32. Jen, C.K. Similarities and Differences between Fiber Acoustics and Fiber Optics. In Proceedings of the IEEE 1985 Ultrasonics Symposium, San Francisco, CA, USA, 16-18 October 1985; Volume 2, pp. 1128-1133.

33. Mangognia, A.; Kucera, C.; Guerrier, J.; Furtick, J.; Hawkins, T.; Dragic, P.D.; Ballato, J. Spinel-derived single mode optical fiber. Opt. Mater. Express 2013, 3, 511-518. [CrossRef]

34. Dragic, P.D.; Ryan, C.; Kucera, C.J.; Cavillon, M.; Tuggle, M.; Jones, M.; Hawkins, T.W.; Yablon, A.D.; Stolen, R.; Ballato, J. Single- and few-moded lithium aluminosilicate optical fiber for athermal Brillouin strain sensing. Opt. Lett. 2015, 40, 5030-5033. [CrossRef] [PubMed]

35. Dragic, P.D.; Cavillon, M.; Ballato, A.; Ballato, J. A unified materials approach to mitigating optical nonlinearities in optical fiber. II. B. The optical fiber, material additivity and the nonlinear coefficients. Int. J. Appl. Glass Sci. 2018, 9, 307-318. [CrossRef]

36. Auld, B.A. Acoustic Fields and Waves in Solids; John Wiley: Hoboken, NY, USA, 1973.

37. Mason, W.P. Physical Acoustics and the Properties of Solids; Van Nostrand: Princeton, NJ, USA, 1958.

38. Thomas, P.J.; Rowell, N.L.; van Driel, H.M.; Stegeman, G.I. Normal acoustic modes and Brillouin scattering in single-mode optical fibers. Phys. Rev. B 1979, 19, 4986-4998. [CrossRef]

39. Jen, C.-K.; Safaai-Jazi, A.; Farnell, G.W. Leaky Modes in Weakly Guiding Fiber Acoustic Waveguides. IEEE Trans. Ultrason. Ferroelectr. Freq. Control 1986, 33, 634-643.

40. Jen, C.-K.; Goto, N. Backward Collinear Guided-Wave-Acousto-Optic Interactions in Single-Mode Fibers. J. Lightwave Technol. 1989, 7, 2018-2023. [CrossRef]

41. Jen, C.-K.; Oliveira, J.E.B.; Goto, N.; Abe, K. Role of Guided Acoustic Wave Properties in Single-Mode Optical Fiber Design. Electron. Lett. 1988, 24, 1419-1420. [CrossRef]

42. Shibata, N.; Azuma, Y.; Horiguchi, T.; Tateda, M. Identification of longitudinal acoustic modes guided in the core region of a single-mode optical fiber by Brillouin gain spectra measurements. Opt. Lett. 1988, 13, 595-597. [CrossRef] [PubMed]

43. Shibata, N.; Okamoto, K.; Azuma, Y. Longitudinal acoustic modes and Brillouin-gain spectra for $\mathrm{GeO}_{2}$-doped-core single-mode fibers. J. Opt. Soc. Am. B 1989, 6, 6-1167. [CrossRef]

44. Dragic, P.D. Novel dual-Brillouin-frequency optical fiber for distributed temperature sensing. Proc. SPIE 2009, 7197, 719710.

45. Koyamada, Y.; Sato, S.; Nakamura, S.; Sotobayashi, H.; Chujo, W. Simulating and Designing Brillouin Gain Spectrum in Single-Mode Fibers. J. Lightwave Technol. 2004, 22, 631-639. [CrossRef]

46. Dong, L. Limits of Stimulated Brillouin Scattering Suppression in Optical Fibers with Transverse Acoustic Waveguide Designs. J. Lightwave Technol. 2010, 28, 3156-3161.

47. Tuggle, M.; Kucera, C.; Hawkins, T.; Sligh, D.; Runge, A.F.J.; Peacock, A.C.; Dragic, P.; Ballato, J. Highly nonlinear yttrium-aluminosilicate optical fiber with a high intrinsic stimulated Brillouin scattering threshold. Opt. Lett. 2017, 42, 4849-4852. [CrossRef] [PubMed]

48. Mermelstein, M.D.; Ramachandran, S.; Fini, J.M.; Ghalmi, S. SBS gain efficiency measurements and modeling in a $1714 \mu \mathrm{m}^{2}$ effective area $\mathrm{LP}_{08}$ higher-order mode optical fiber. Opt. Express 2007, 15, 15952-15963. [CrossRef] [PubMed]

49. Agrawal, G.P. Nonlinear Fiber Optics, 2nd ed.; Academic Press: San Diego, CA, USA, 1995.

50. Fleming, J.W. Dispersion in $\mathrm{GeO}_{2}-\mathrm{SiO}_{2}$ glasses. Appl. Opt. 1984, 23, 4486-4493. [CrossRef] [PubMed]

51. Haake, S.J.; Patterson, E.A. The dispersion of birefringence in photoelastic materials. Strain 1993, $29,3-7$. [CrossRef]

52. Dragic, P.D.; Ballato, J.; Morris, S.; Hawkins, T. Pockels' coefficients of alumina in aluminosilicate optical fiber. J. Opt. Soc. Am. B 2013, 30, 244-250. [CrossRef]

53. Jog, E.S.; Krishnan, R.S. Dispersion of the Photoelastic Constants of Fused Silica. Nature 1957, 179, 540-541. [CrossRef]

54. Jen, C.K.; Neron, C.; Bussiere, J.F.; Abe, K.; Li, L.; Lowe, R.; Kushibiki, J. Acoustic Microscopy of Cladded Optical Fibrers. In Proceedings of the IEEE Ultrasonics Symposium, Montreal, QC, Canada, 3-6 October 1989; pp. 831-835.

55. Jen, C.-K.; Neron, C.; Shang, A.; Abe, K.; Bonnell, L.; Kushibiki, J. Acoustic Characterization of Silica Glass. J. Am. Ceram. Soc. 1993, 76, 712-716. [CrossRef] 
56. Ohmori, Y.; Okazawi, H.; Hatakeyama, I.; Takata, H. Very Low OH Content $\mathrm{P}_{2} \mathrm{O}_{5}$-Doped Silica Fibres. Electron. Lett. 1979, 15, 616-618. [CrossRef]

57. Niklès, M.; Thevenaz, L.; Robert, P.A. Brillouin Gain Spectrum Characterization in Single-Mode Optical Fibers. J. Lightwave Technol. 1997, 15, 1842-1851. [CrossRef]

58. Lagakos, N.; Bucaro, J.A.; Hughes, R. Acoustic sensitivity predictions of single-mode optical fibers using Brillouin scattering. Appl. Opt. 1980, 19, 3668-3670. [CrossRef] [PubMed]

59. Shiraki, K.; Ohashi, M. Sound Velocity Measurement Based on Guided Acoustic-Wave Brillouin Scattering. IEEE Photonics Technol. Lett. 1992, 4, 1177-1180. [CrossRef]

60. Zou, W.; He, Z.; Hotate, K. Experimental study of Brillouin scattering in fluorine-doped single-mode optical fibers. Opt. Express 2008, 16, 18804-18812. [CrossRef] [PubMed]

61. Xiao, H.; Ren, G.; Dong, Y.; Li, H.; Xiao, S.; Wu, B.; Jian, S. A numerical analysis of $\mathrm{GeO}_{2}$-doped multi-step index single-mode fiber for stimulated Brillouin scattering. J. Opt. 2018, 20, 065701. [CrossRef]

62. Xu, Y.; Ren, M.; Lu, Y.; Lu, P.; Lu, P.; Bao, X.; Wang, L.; Messaddeq, Y.; LaRochelle, S. Multi-parameter sensor based on stimulated Brillouin scattering in inverse-parabolic graded-index fiber. Opt. Lett. 2016, 41, 1138-1141. [CrossRef] [PubMed]

63. Winkelmann, A.; Schott, O. On the elasticity and the tensile and compressive strength of several new glasses in their dependence on the chemical composition. Ann. Phys. Chem. 1894, 51, 697-730. [CrossRef]

64. Dragic, P.; Ballato, J. 120 Years of Optical Glass Science. Opt. Photonics News 2014, 25, 44-51. [CrossRef]

65. Dragic, P.D. Brillouin spectroscopy of Nd-Ge co-doped silica fibers. J. Non-Cryst. Solids 2009, 355, $403-413$. [CrossRef]

66. Bloss, F.D. Relationship between Density and Composition in Mol Per Cent for Some Solid Solution Series. Am. Mineral. 1952, 37, 966-981.

67. Dragic, P.D. The Acoustic Velocity of Ge-Doped Silica Fibers: A Comparison of Two Models. Int. J. Appl. Glass Sci. 2010, 1, 330-337. [CrossRef]

68. Dragic, P.D. Simplified model for effect of Ge doping on silica fibre acoustic properties. Electron. Lett. 2009, 45, 256-257. [CrossRef]

69. Dragic, P.; Law, P.-C.; Ballato, J.; Hawkins, T.; Foy, P. Brillouin spectroscopy of YAG-derived optical fibers. Opt. Express 2010, 18, 10055-10067. [CrossRef] [PubMed]

70. Cavillon, M.; Furtick, J.; Kucera, C.J.; Ryan, C.; Tuggle, M.; Jones, M.; Hawkins, T.W.; Dragic, P.; Ballato, J. Brillouin Properties of a Novel Strontium Aluminosilicate Glass Optical Fiber. J. Lightwave Technol. 2016, 34, 1435-1441. [CrossRef]

71. Dragic, P.; Kucera, C.; Furtick, J.; Guerrier, J.; Hawkins, T.; Ballato, J. Brillouin spectroscopy of a novel baria-doped silica glass optical fiber. Opt. Express 2013, 21, 10924-10941. [CrossRef] [PubMed]

72. Dragic, P.D.; Ballato, J.; Morris, S.; Hawkins, T. The Brillouin gain coefficient of Yb-doped aluminosilicate glass optical fibers. Opt. Mater. 2013, 35, 1627-1632. [CrossRef]

73. Dragic, P.D.; Kucera, C.; Ballato, J.; Litzkendorf, D.; Dellith, J.; Schuster, K. Brillouin scattering properties of lanthano-aluminosilicate optical fiber. Appl. Opt. 2014, 53, 5660-5671. [CrossRef] [PubMed]

74. Dragic, P.D.; Pamato, M.G.; Iordache, V.; Bass, J.D.; Kucera, C.J.; Jones, M.; Hawkins, T.W.; Ballato, J. Athermal distributed Brillouin sensors utilizing all-glass optical fibers fabricated from rare earth garnets: LuAG. New J. Phys. 2016, 18, 015004. [CrossRef]

75. Dragic, P.D. Brillouin Gain Reduction Via $\mathrm{B}_{2} \mathrm{O}_{3}$ Doping. J. Lightwave Technol. 2011, 29, 967-973. [CrossRef]

76. Dragic, P.; Ballato, J.; Ballato, A.; Morris, S.; Hawkins, T.; Law, P.-C.; Ghosh, S.; Paul, M.C. Mass density and the Brillouin spectroscopy of aluminosilicate optical fibers. Opt. Mater. Express 2012, 2, 1641-1654. [CrossRef]

77. Guerette, M.; Ackerson, M.R.; Thomas, J.; Yuan, F.; Watson, E.B.; Walker, D.; Huang, L. Structure and Properties of Silica Glass Densified in Cold Compression and Hot Compression. Sci. Rep. 2015, 5, 15343. [CrossRef] [PubMed]

78. Burkhard, D.J.M. Elastic Properties of Alkali Silicate Glasses with Iron Oxide: Relation to Glass Structure. Sol. State Commun. 1997, 101, 903-907. [CrossRef]

79. Jabraoui, H.; Vaills, Y.; Hasnaoui, A.; Badawi, M.; Ouaskit, S. Effect of Sodium Oxide Modifier on Structural and Elastic Properties of Silicate Glass. J. Phys. Chem. B 2016, 120, 13193-13205. [CrossRef] [PubMed]

80. Trejo, R.; Lara-Curzio, E.; Shyam, A.; Kirkham, M.J.; Garcia-Negron, V.; Wang, Y. Physical and Mechanical Properties of Barium Alkali Silicate Glasses for SOFC Sealing Applications. In. J. Appl. Glass Sci. 2012, 3, 369-379. [CrossRef] 
81. Vasantharani, P.; Neelayathashi alias Vichitra, S. Structural and Elastic Studies of Strontium Doped Manganese Borate Glasses. IOSR J. Appl. Phys. 2017, 9, 44-49. [CrossRef]

82. Gerlich, D.; Wolf, M.; Yaacov, I.; Nissensen, B. Thermelastic Properties of ULE ${ }^{\circledR}$ Titanium Silicate Glass. J. Non-Cryst. Solids 1976, 21, 243-249. [CrossRef]

83. Weigel, C.; Le Losq, C.; Vialla, R.; Dupas, C.; Clément, S.; Neuville, D.R.; Rufflé, B. Elastic moduli of $\mathrm{XAlSiO}_{4}$ aluminosilicate glasses: Effects of charge-balancing cations. J. Non-Cryst. Solids 2016, 447, 267-272. [CrossRef]

84. Huang, Y.Y.; Hunt, J.L.; Stevens, J.R. Determination of elastic constants in isotropic silicate glasses by Brillouin scattering. J. Appl. Phys. 1973, 44, 3589-3592. [CrossRef]

85. Yablon, A.D. Optical and Mechanical Effects of Frozen-in Stresses and Strains in Optical Fibers. IEEE J. Sel. Top. Quantum Electron. 2004, 10, 300-311. [CrossRef]

86. Zou, W.; He, Z.; Yablon, A.D.; Hotate, K. Effect of draw-induced residual elastic and inelastic strains on Brillouin frequency shift in optical fibers. In Proceedings of the OFC/NFOEC 2007-2007 Conference on Optical Fiber Communication and the National Fiber Optic Engineers Conference, Anaheim, CA, USA, 25-29 March 2007. Paper OTuC3.

87. Gulistan, A.; Rahman, M.M.; Ghosh, S.; Rahman, B.M.A. Tailoring light-sound interactions in a single mode fiber for the high-power transmission or sensing applications. In Proceedings of the Third International Conference on Photonic Solutions, Pattaya, Thailand, 5 March 2018; Volume 10714, p. 1071403.

88. Ward, B.; Spring, J. Finite element analysis of Brillouin gain in SBS-suppressing optical fibers with non-uniform acoustic velocity profiles. Opt. Express 2009, 17, 15685-15699. [CrossRef] [PubMed]

89. Sriratanavaree, S.; Azizur Rahman, B.M.; Leung, D.M.H.; Kejalakshmy, N.; Grattan, K.T.V. Full-Vectorial Finite-Element Analysis of Acoustic Modes in Silica Waveguides. IEEE J. Quantum Electron. 2014, 50, 1006-1013. [CrossRef]

90. Zou, W.; He, Z.; Hotate, K. Two-Dimensional Finite-Element Modal Analysis of Brillouin Gain Spectra in Optical Fibers. IEEE Photonics Technol. Lett. 2006, 18, 2487-2489. [CrossRef]

91. Mamdem, Y.S.; Phéron, X.; Taillade, F.; Jaoüen, Y.; Gabet, R.; Lanticq, V.; Moreau, G.; Boukenter, A.; Ouerdane, Y.; Lesoille, S.; et al. Two-dimensional FEM Analysis of Brillouin Gain Spectra in Acoustic Guiding and Antiguiding Single Mode Optical Fibers. In Proceedings of the COMSOL Conference, Paris, France, 17-19 November 2010.

92. Zervas, M.N.; Codemard, C.A. High Power Fiber Lasers: A Review. IEEE J. Sel. Top. Quantum Electron. 2014, 20, 0904123. [CrossRef]

93. Dragic, P.D.; Ward, B.G. Accurate Modeling of the Intrinsic Brillouin Linewidth via Finite-Element Analysis. IEEE Photonics Technol. Lett. 2010, 22, 1698-1700. [CrossRef]

94. Law, P.-C.; Liu, Y.-S.; Croteau, A.; Dragic, P. Acoustic coefficients of $\mathrm{P}_{2} \mathrm{O}_{5}$-doped silica fiber: Acoustic velocity, acoustic attenuation, and thermo-acoustic coefficient. Opt. Mater. Express 2011, 1, 686-699. [CrossRef]

95. Ballato, J.; Dragic, P. Rethinking Optical Fiber: New Demands, Old Glasses. J. Am. Ceram. Soc. 2013, 96, 2675-2692. [CrossRef]

96. Anan'ev, A.V.; Bogdanov, V.N.; Champagnon, B.; Ferrari, M.; Karapetyan, G.O.; Maksimov, L.V.; Smerdin, S.N.; Solovyev, V.A. Origin of Rayleigh scattering and anomaly of elastic properties in vitreous and molten $\mathrm{GeO}_{2}$. J. Non-Cryst. Solids 2008, 354, 3049-3058. [CrossRef]

97. Law, P.-C.; Croteau, A.; Dragic, P.D. Acoustic coefficients of $\mathrm{P}_{2} \mathrm{O}_{5}$-doped silica fiber: The strain-optic and strain-acoustic coefficients. Opt. Mater. Express 2012, 2, 391-404. [CrossRef]

98. Ballato, J.; Cavillon, M.; Dragic, P. A unified materials approach to mitigating optical nonlinearities in optical fiber. I. Thermodynamics of optical scattering. Int. J. Appl. Glass Sci. 2018, 9, 263-277. [CrossRef]

99. Dragic, P.D.; Cavillon, M.; Ballato, A.; Ballato, J. A unified materials approach to mitigating optical nonlinearities in optical fiber. II. A. Material additivity models and basic glass properties. Int. J. Appl. Glass Sci. 2018, 9, 278-287. [CrossRef]

100. Cavillon, M.; Kucera, C.; Hawkins, T.; Dawson, J.; Dragic, P.D.; Ballato, J. A unified materials approach to mitigating optical nonlinearities in optical fiber. III. Canonical examples and materials road map. Int. J. Appl. Glass Sci. 2018, 9, 447-470. [CrossRef]

101. Krischer, C. Optical Measurements of Ultrasonic Attenuation and Reflection Losses in Fused Silica. J. Acoust. Soc. Am. 1970, 48, 1086-1092. [CrossRef]

102. Law, P.-C.; Dragic, P.D. Wavelength dependence of the Brillouin spectral width of boron doped germanosilicate optical fibers. Opt. Express 2010, 18, 18852-18865. [CrossRef] [PubMed] 
103. Dragic, P.; Hawkins, T.; Foy, P.; Morris, S.; Ballato, J. Sapphire-derived all-glass optical fibres. Nat. Photonics 2012, 6, 627-633. [CrossRef]

104. Prod'homme, L. A new approach to the thermal change in the refractive index of glasses. Phys. Chem. Glasses 1960, 1, 119-122.

105. Kishida, K.; Yamauchi, Y.; Guzik, A. Study of Optical Fibers Strain-Temperature Sensitivities Using Hybrid Brillouin-Rayleigh System. Photonics Sens. 2014, 4, 1-11. [CrossRef]

106. Lu, X.; Soto, M.A.; Thévenaz, L. Impact of the Fiber Coating on the Temperature Response of Distributed Optical Fiber Sensors at Cryogenic Ranges. J. Lighwave Technol. 2018, 36, 961-967. [CrossRef]

107. Gu, H.; Dong, H.; Zhang, G.; He, J.; Pan, H. Effects of Polymer Coatings on Temperature Sensitivity of Brillouin Frequency Shift Within Double-Coated Fiber. IEEE Sens. J. 2013, 13, 864-869. [CrossRef]

108. Peselnick, L.; Meister, R.; Wilson, W.H. Pressure Derivatives of Elastic Moduli of Fused Quartz to $10 \mathrm{~kb}$. J. Phys. Chem. Solids 1967, 28, 635-639. [CrossRef]

109. Gerlich, D.; Kennedy, G.C. Second Pressure Derivatives of the Elastic Moduli of Fused Quartz. J. Phys. Chem. Solids 1978, 39, 1189-1191. [CrossRef]

110. Tielbürger, D.; Merz, R.; Ehrenfels, R.; Hunklinger, S. Thermally Activated Relaxation Processes in Vitreous Silica: An Investigation by Brillouin Scattering at High Pressures. Phys. Rev. B 1992, 45, 2750-2760. [CrossRef]

111. Pine, A.S. Brillouin Scattering Study of Acoustic Attenuation in Fused Quartz. Phys. Rev. 1969, 185, 1187-1193. [CrossRef]

112. Masnik, J.E.; Kieffer, J.; Bass, J.D. The complex mechanical modulus as a structural probe: The case of alkali borate liquids and glasses. J. Chem. Phys. 1995, 103, 9907-9917. [CrossRef]

113. Hertling, J.; Baeßler, S.; Rau, S.; Kasper, G.; Hunklinger, S. Internal friction and hypersonic velocity in vitreous germania under high pressure. J. Non-Cryst. Sol. 1998, 226, 129-137. [CrossRef]

114. Parker, T.R.; Farhadiroushan, M.; Handerek, V.A.; Rogers, A.J. A Fully Distributed Simultaneous Strain and Temperature Sensor using Spontaneous Brillouin Backscatter. IEEE Photonics Technol. Lett. 1997, 9, 979-981. [CrossRef]

115. Kee, H.H.; Lees, G.P.; Newson, T.P. All-fiber system for simultaneous interrogation of distributed strain and temperature sensing by spontaneous Brillouin scattering. Opt. Lett. 2000, 25, 695-697. [CrossRef] [PubMed]

116. Maughan, S.M.; Kee, H.H.; Newson, T.P. Simultaneous distributed fibre temperature and strain sensor using microwave coherent detection of spontaneous Brillouin backscatter. Meas. Sci. Technol. 2001, 12, 834-842. [CrossRef]

117. Bao, X.; Webb, D.J.; Jackson, D.A. Combined distributed temperature and strain sensor based on Brillouin loss in an optical fiber. Opt. Lett. 1994, 19, 141-143. [CrossRef] [PubMed]

118. Zou, W.; He, Z.; Hotate, K. Complete discrimination of strain and temperature using Brillouin frequency shift and birefringence in a polarization-maintaining fiber. Opt. Express 2009, 17, 1248-1255. [CrossRef] [PubMed]

119. Zou, W.; He, Z.; Hotate, K. Demonstration of Brillouin Distributed Discrimination of Strain and Temperature Using a Polarization-Maintaining Optical Fiber. IEEE Photonics Technol. Lett. 2010, 22, 526-528. [CrossRef]

120. Dong, Y.; Chen, L.; Bao, X. High-Spatial-Resolution Time-Domain Simultaneous Strain and Temperature Sensor Using Brillouin Scattering and Birefringence in a Polarization-Maintaining Fiber. IEEE Photonics Technol. Lett. 2010, 22, 1364-1366. [CrossRef]

121. Ding, M.; Mizuno, Y.; Nakamura, K. Discriminative strain and temperature measurement using Brillouin scattering and fluorescence in erbium-doped optical fiber. Opt. Express 2014, 22, 24706-24712. [CrossRef] [PubMed]

122. Li, M.-J.; Li, S.; Derick, J.A.; Stone, J.S.; Chow, B.C.; Bennett, K.W.; Sutherlin, D.M. Dual Core Optical Fiber for Distributed Brillouin Fiber Sensors. In Proceedings of the Asia Communications and Photonics Conference, Shanghai, China, 11-14 November 2014.

123. Zaghloul, M.A.S.; Wang, M.; Milione, G.; Li, M.-J.; Li, S.; Huang, Y.-K.; Wang, T.; Chen, K.P. Discrimination of Temperature and Strain in Brillouin Optical Time Domain Analysis Using a Multicore Optical Fiber. Sensors 2018, 18, 1176. [CrossRef] [PubMed]

124. Mizuno, Y.; Hayashi, N.; Tanaka, H.; Wada, Y.; Nakamura, K. Brillouin scattering in multi-core optical fibers for sensing applications. Sci. Rep. 2015, 5, 11388. [CrossRef] [PubMed]

125. Zhao, Z.; Soto, M.A.; Tang, M.; Thévenaz, L. Distributed shape sensing using Brillouin scattering in multi-core fibers. Opt. Express 2016, 24, 25211-25223. [CrossRef] [PubMed] 
126. Zhao, Z.; Soto, M.A.; Tang, M.; Thévenaz, L. Demonstration of distributed shape sensing based on Brillouin scattering in multi-core fibers. Proc. SPIE 2017, 10323, 1032393.

127. Li, A.; Wang, Y.; Fang, J.; Li, M.-J.; Kim, B.Y.; Shieh, W. Few-mode fiber multi-parameter sensor with distributed temperature and strain discrimination. Opt. Lett. 2015, 40, 1488-1491. [CrossRef] [PubMed]

128. Weng, Y.; Ip, E.; Pan, Z.; Wang, T. Single-end simultaneous temperature and strain sensing techniques based on Brillouin optical time domain reflectometry in few-mode fibers. Opt. Express 2015, 23, 9024-9039. [CrossRef] [PubMed]

129. Pradhan, P.; Sengupta, D.; Wang, L.; Tremblay, C.; LaRochelle, S.; Ung, B. The Brillouin gain of vector modes in few-mode fiber. Sci. Rep. 2017, 7, 1552. [CrossRef] [PubMed]

130. Zhang, Y.-J.; Gao, H.-L.; Fu, X.-H.; Tian, Y.-S. Characterization of Brillouin scattering in a few-mode fiber. Acta Phys. Sin. 2017, 66, 024207.

131. Xu, Y.; Ren, M.; Lu, Y.; Lu, P.; Bao, X.; LaRochelle, S. Multi-parameter sensing based on the stimulated Brillouin scattering of higher-order acoustic modes in OAM fiber. Proc. SPIE 2015, 9634, 96340L.

132. Wu, H.; Tang, M.; Wang, M.; Zhao, C.; Zhao, Z.; Wang, R.; Liao, R.; Fu, S.; Yang, C.; Tong, W.; et al. Few-mode optical fiber based simultaneously distributed curvature and temperature sensing. Opt. Express 2017, 25, 12722-12732. [CrossRef] [PubMed]

133. Lee, C.C.; Chiang, P.W.; Chi, S. Utilization of a Dispersion-Shifted Fiber for Simultaneous Measurement of Distributed Strain and Temperature Through Brillouin Frequency Shift. IEEE Photonics Technol. Lett. 2001, 12, 1094-1096. [CrossRef]

134. Liu, X.; Bao, X. Brillouin Spectrum in LEAF and Simultaneous Temperature and Strain Measurement. J. Lightwave Technol. 2012, 30, 1053-1059. [CrossRef]

135. Li, M.-J.; Li, S.; Stone, J.S. Novel Optical Fibers for Distributed Sensor Applications. Proc. SPIE 2017, $10323,103231 \mathrm{C}$.

136. Zou, W.; He, Z.; Kishi, M.; Hotate, K. Stimulated Brillouin scattering and its dependences on strain and temperature in a high-delta optical fiber with F-doped depressed inner cladding. Opt. Lett. 2007, 32, 600-602. [CrossRef] [PubMed]

137. Zou, W.; He, Z.; Hotate, K. Acoustic modal analysis and control in w-shaped triple-layer optical fibers with highly-germanium-doped core and F-doped cladding. Opt. Express 2008, 16, 10006-10017. [CrossRef] [PubMed]

138. Dragic, P.D. Distributed temperature sensing via Brillouin-tailored optical fiber. Proc. SPIE 2009, 7316, 731605.

139. Dragic, P.; Cavillon, M.; Ballato, J. On the thermo-optic coefficient of $\mathrm{P}_{2} \mathrm{O}_{5}$ in $\mathrm{SiO}_{2}$. Opt. Mater. Express 2017, 7, 3654-3661. [CrossRef]

140. Li, H.-L.; Zhang, W.; Huang, Y.-D.; Peng, J.-D. Acoustical longitudinal mode coupling in w-shaped Al/Ge Co-doped fibre. Chin. Phys. B 2011, 20, 104211. [CrossRef]

141. Xiao, S.; Dong, Y.; Xiao, H.; Ren, G.; Jen, S. SMFs with a Ge/F Co-Doped Inner Core for SBS-Based Discriminative Sensing of Temperature and Strain. IEEE Sens. J. 2018, 18, 1087-1093. [CrossRef]

142. Hotate, K.; Zou, W.; Yamashita, R.K.; He, Z. Distributed Discrimination of Strain and Temperature Based on Brillouin Dynamic Grating in an Optical Fiber. Photonics Sens. 2013, 3, 332-344. [CrossRef]

143. Lu, Y.; Qin, Z.; Lu, P.; Zhou, D.; Chen, L.; Bao, X. Distributed Strain and Temperature Measurement by Brillouin Beat Spectrum. IEEE Photonics Technol. Lett. 2013, 25, 1050-1053. [CrossRef]

144. Shiraki, K.; Ohashi, M.; Tateda, M. Performance of Strain-Free Stimulated Brillouin Scattering Suppression Fiber. J. Lightwave Technol. 1996, 14, 549-554. [CrossRef]

145. Ohashi, M.; Tateda, M. Design of Strain-Free-Fiber with Nonuniform Dopant Concentration for Stimulated Brillouin Scattering Suppression. J. Lightwave Technol. 1993, 11, 1941-1945. [CrossRef]

146. Evert, A.; James, A.; Hawkins, T.; Foy, P.; Stolen, R.; Dragic, P.; Dong, L.; Rice, R.; Ballato, J. Longitudinally-graded optical fibers. Opt. Express 2012, 20, 17393-17401. [CrossRef] [PubMed]

147. Dragic, P.D.; Mangognia, A.; Ballato, J. Chirped fiber Brillouin frequency-domain distributed sensing. Opt. Eng. 2014, 53, 056117. [CrossRef]

148. Dragic, P.D.; Ryan, C.; Kucera, C.J.; Cavillon, M.; Tuggle, M.; Jones, M.; Hawkins, T.W.; Yablon, A.D.; Stolen, R.; Ballato, J. Lithium Aluminosilicate Optical Fiber for Brillouin-Based Distributed Sensing. In Proceedings of the Advanced Photonics Congress, Vancouver, BC, Canada, 18-20 July 2016. Paper SeM2D.

149. Mizuno, Y.; Nakamura, K. Brillouin Scattering in Polymer Optical Fibers: Fundamental Properties and Potential Use in Sensors. Polymers 2011, 3, 886-898. [CrossRef] 
150. Dragic, P.D.; Martin, S.W.; Ballato, A.; Ballato, J. On the Anomalously Strong Dependence of the Acoustic Velocity of Alumina on Temperature in Aluminosilicate Glass Optical Fibers-Part I: Material Modeling and Experimental Validation. Int. J. Appl. Glass Sci. 2016, 7, 3-10. [CrossRef]

151. Ballato, A.; Dragic, P.D.; Martin, S.W.; Ballato, J. On the Anomalously Strong Dependence of the Acoustic Velocity of Alumina on Temperature in Aluminosilicate Glass Optical Fibers-Part II: Acoustic Properties of Alumina and Silica Polymorphs, and Approximations of the Glassy State. Int. J. Appl. Glass Sci. 2016, 7, 11-26. [CrossRef]

152. Cavillon, M.; Dragic, P.D.; Ballato, J. Additivity of the coefficient of thermal expansion in silicate optical fibers. Opt. Lett. 2017, 42, 3650-3653. [CrossRef] [PubMed]

153. Tao, G.; Abouraddy, A.F.; Stolyarov, A.M. Multimaterial Fibers. Int. J. Appl. Glass Sci. 2012, 3, 349-368. [CrossRef]

154. Ballato, J.; Ebendorff-Heidepriem, H.; Zhao, J.; Petit, L.; Troles, J. Glass and Process Development for the Next Generation of Optical Fibers. Fibers 2017, 5, 11. [CrossRef]

155. Morris, S.; Ballato, J. Molten-core fabrication of novel optical fibers. Am. Ceram. Soc. Bull. 2013, 92, $24-29$.

156. Wu, F.; Machewirth, D.; Snitzer, E.; Sigel, G.H. An efficient single-mode $\mathrm{Nd}^{3+}$ fiber laser prepared by the sol-gel method. J. Mater. Res. 1994, 9, 2703-2705. [CrossRef]

157. Halder, A.; Bhadra, S.K.; Bysakh, S.; Paul, M.C.; Das, S. Strong and Broad Visible Emission of Bismuth Doped Nano-Phase Separated Ytteria-alumina-silica Optical Fibers. Curr. Nanosci. 2016, 12, 309-315. [CrossRef]

158. Schuster, K.; Unger, S.; Aichele, C.; Lindner, F.; Grimm, S.; Litzkendorf, D.; Kobelke, J.; Bierlich, J.; Wondraczek, K.; Bartelt, H. Material and technology trends in fiber optics. Adv. Opt. Technol. 2014, 3, 447-468. [CrossRef]

159. Geng, J.; Staines, S.; Blake, M.; Jiang, S. Distributed fiber temperature and strain sensor using coherent radio-frequency detection of spontaneous Brillouin scattering. Appl. Opt. 2007, 46, 5928-5932. [CrossRef] [PubMed]

(C) 2018 by the authors. Licensee MDPI, Basel, Switzerland. This article is an open access article distributed under the terms and conditions of the Creative Commons Attribution (CC BY) license (http:/ / creativecommons.org/licenses/by/4.0/). 